Continental Shelf Research

May 2016, Volume 119, Pages 14-29

http://dx.doi.org/10.1016/..csr.2016.03.006

http://archimer.ifremer.fr/doc/00318/42941/

(C) 2016 Elsevier Ltd. All rights reserved.

\title{
Modelling cyclonic eddies in the Delagoa Bight region
}

\author{
Cossa O. ${ }^{1,4}$, Pous Stephane ${ }^{1,2,{ }^{*}}$, Penven Pierrick ${ }^{1,3}$, Capet Xavier $^{2}$, Reason C.J.C. ${ }^{1}$ \\ ${ }^{1}$ Department of Oceanography, University of Cape Town, South Africa \\ ${ }^{2}$ Sorbonne Universités (UPMC, Univ Paris 06)-CNRS-IRD-MNHN, LOCEAN Laboratory, Paris, France \\ ${ }^{3}$ LMI ICEMASA, Laboratoire de Physique des Océans, UMR 6523 (CNRS, Ifremer, IRD, UBO), \\ Plouzané, France \\ ${ }^{4}$ Instituto Nacional de Hidrografia e Navegação, Maputo, Mozambique \\ * Corresponding author : Stéphane Pous, Tel.:+33 01442746 27; fax: +33 0144273805 ; email \\ address : pous@mnhn.fr
}

\begin{abstract}
:
The objective of this study is to document and shed light on the circulation around the Delagoa Bight region in the southern Mozambique Channel using a realistic modelling approach. A simulation including mesoscale forcings at the boundaries of our regional configuration succeeds in reproducing the general circulation in the region as well as the existence of a semi-permanent cyclonic eddy, whose existence is attested by in situ measurements in the Bight. Characterised by a persistent local minimum in SSH located around $26{ }^{\circ} \mathrm{S}-$ $34{ }^{\circ} \mathrm{E}$, this cyclonic eddy termed herein the Delagoa Bight lee eddy occurs about $25 \%$ of the time with no clear seasonal preference. Poleward moving cyclones, mostly generated further north, occur another $25 \%$ of the time in the Bight area. A tracking method applied to eddies generated in Delagoa Bight using model outputs as well as AVISO data confirms the model realism and provides additional statistics. The diameter of the eddy core varies between 61 and $147 \mathrm{~km}$ and the average life time exceeds 20 days. Additional model analyses reveal the systematic presence of negative vorticity in the Bight that can organise and form a Delagoa Bight lee eddy depending on the intensity of an intermittent southward flow along the shore and the spatial distribution of surrounding mesoscale features. In addition, the model solution shows other cyclonic eddies generated near Inhambane and eventually travelling through the Bight. Their generation and pathways appears to be linked with large Mozambique Channel rings.
\end{abstract}

\section{Highlights}

- Mean circulation and mesoscale activity near Delagoa Bight are realistically simulated. The model produces a semi-permanent cyclonic lee eddy in Delagoa Bight. Favourable conditions to the onset of the lee eddy are described. Transient cyclonic eddies travelling through the Bight are generated north of $\mathrm{P}$. Závora.

Keywords: Delagoa Bight, cyclonic lee eddy, coastal countercurrent, numerical model, Mozambique Channel, shelf processes 


\section{Introduction}

The Delagoa Bight, on the south-east African coast, is one of the largest coastal indentations in the south-west Indian Ocean [Lamont et al., 2010] and is located right offshore of the Mozambican capital, Maputo (Figure 1a). Situated south of the Mozambique Channel, it is influenced by oceanic features travelling through the Channel as well as those coming from the southern tip of Madagascar [Lutjeharms, 2006a]. This is also the place where the Agulhas Current, the largest western boundary current in the southern hemisphere and of global climatic importance, finds its sources [Lutjeharms, 2006a].

The flow in the Delagoa Bight is dominated by a topographically trapped cyclonic mesoscale circulation, the Delagoa Bight lee eddy (hereafter DBLE), that is generally centred around $26^{\circ} \mathrm{S} 34^{\circ} \mathrm{E}$ [Lutjeharms and da Silva, 1988; Lutjeharms, 2006b; Lamont et al., 2010]. Typically, the DBLE has a diameter of $180 \mathrm{~km}$ [Lutjeharms and da Silva, 1988]. Although Lutjeharms and da Silva [1988] have described it as a quasi-permanent feature, observations by Lamont et al. [2010] revealed its intermittency. Studies on sediment distribution on the continental shelf along the Mozambican coast also suggest the persistence of a DBLE [Martin 1981].

The DBLE is presumably associated with high levels of mixing over the upper levels (around $50-75 \mathrm{~m}$ ), [Lutjeharms and da Silva, 1988; Lamont et al., 2010] which would account for temperature-salinity characteristics in its vicinity being completely modified from those prevalent in the Mozambique Channel. Equatorial Surface Waters and Subtropical Waters are mixed out in the eddy, whereas the core of the eddy contains Antarctic Intermediate Water which upwells from depths of around $1000 \mathrm{~m}$ [Lutjeharms and da Silva, 1988].

Based on in situ data and infra-red satellite imagery, Lutjeharms and da Silva [1988] gave insight into the Delagoa Bight circulation, including the possible mechanisms of generation of the DBLE by the Mozambique Current. This being said, the circulation characteristics are not well-established in the region. The prevalence of the Mozambique current as a continuous jet has been questioned [Lutjeharms, 2006a; DiMarco et al., 2002; Donguy and Piton, 1991; Saetre and da Silva, 1984]. Indeed, modelling studies and satellite altimetry analyses show the dominance of a southward transport as a consequence of a train of anticyclonic eddies [Biastoch and Krauss, 1999; Schouten et al., 2003], the Mozambique Channel rings [Halo et al., 2014a]. It remains to be clarified whether this result suggested for the central Mozambique Channel also applies to the specific region 
offshore of Delagoa Bight, where no long-term direct observations of the alongshore circulation have been undertaken.

More recently, Roberts et al. [2014] described an eddy dipole (with a cyclone to the south of an anticyclone) along the western slope of the Mozambique Channel and its interaction with the western continental shelf leading to slope upwelling and offshore export of chlorophyll-enriched shelf water. Lamont et al. [2010] used in situ and satellite observations to investigate the impact of the passing anticyclones on the DBLE.

Cyclonic eddies are generally associated with vertical pumping of nutrients, and consequently with enhancement of oceanic primary productivity [McGillicuddy and Robinson, 1997]. In the Delagoa Bight, high levels of productivity offer a suitable environment for the development of a rich marine ecosystem [Lamont et al., 2010].Thus, the Delagoa Bight has been identified as the second richest area after the Bank of Sofala in terms of shrimp fisheries in Mozambique [Paula et al., 1998]. The lifespan of the DBLE is supposed to be crucial for maintaining the productivity.

Here we present the results of a regional ocean model configuration which has been designed specifically to resolve the local ocean circulation in the Delagoa Bight. Although in situ observations have been collected in the region [Lamont et al., 2010], the use of an ocean model can help better understand the dynamical ocean processes operating in the Bight and provide a more complete description of the DBLE and associated

processes. This model simulation is also able to identify new processes of importance such as the generation of cyclonic eddies by the interaction of Mozambique Channel rings with the topography north of Delagoa Bight.

\section{Material and methods}

\subsection{The Regional Ocean Modelling System}

The Regional Ocean Modelling System (ROMS) is used for the numerical experiments. ROMS is a free surface regional ocean model which solves the primitive equations based on the Boussinesq and hydrostatic approximations, using a topography following vertical coordinate. This is a robust model, with capability of resolving realistically and efficiently basin-scale, regional and coastal ocean processes [Shchepetkin and McWilliams, 2005]. This is achieved by the combination of a mode splitting algorithm for the time stepping and 
higher order numerical schemes in space and time. The model uses the K-profile (KPP) scheme of Large et al. [1994] for vertical mixing. To minimise the problem of spurious diapycnal diffusion associated with the topography following vertical coordinate, the third order upstream advection scheme used for tracers is split into a fourth order advection scheme and a diffusion component in the form of a rotated biharmonic operator [Marchesiello et al., 2009]. Active, implicit, upstream-biased radiation conditions are used in addition to sponge and nudging layers at the open boundaries [Marchesiello et al., 2001]. ROMS has been successfully applied in several recent studies in the Mozambique Channel region [e.g., Collins et al., 2014; Halo et al., 2014a; Manyilizu et al., 2014].

\subsection{The Delagoa Bight ocean model configuration}

A specific model configuration is set up using ROMSTOOLS [Penven et al., 2008] to investigate the impacts of the passing anticyclones from both the Mozambique Channel and the southern tip of Madagascar in the region of Delagoa Bight. It covers the area limited by $30.1^{\circ} \mathrm{E}$ and $43.0^{\circ} \mathrm{E}$ in longitude and $22.1^{\circ} \mathrm{S}$ and $30.8^{\circ} \mathrm{S}$ in latitude. The horizontal grid resolution is $1 / 10^{\circ}$ (approximately $9.9 \mathrm{~km}$ in the region) with 50 levels in the vertical. The stretching parameters determining the vertical coordinate are chosen as theta_s $=5.5$, theta_b $=0$ and $h c=50$ m [Haidvogel and Beckmann, 1999]. For the bottom topography, we use a higher resolution gridded topography from the General Bathymetric Chart of the Oceans [Carpine-Lancre et al., 2003]. To prevent errors in the computation of pressure gradients, the model bathymetry is selectively smoothed such that the slope parameter $\left(r=\left(h_{+1 / 2}-h_{-1 / 2}\right) /\left(h_{+1 / 2}+h_{-1 / 2}\right)\right)$ is below 0.25 [Beckmann and Haidvogel, 1993]. The model grid and bottom topography is portrayed in Figure $1(\mathrm{a}-\mathrm{c})$. Note the Mozambique Ridge at $36^{\circ} \mathrm{E}$ and the wide shelf extending offshore in the Delagoa Bight area. The impact of the bathymetry smoothing is shown in Figure 1(b and c). The difference between unsmoothed and smoothed bathymetries is greatest along the steep topographic slopes in the northern and southern sides of the domain (Figure 1c) but negligible elsewhere, in particular on the Delagoa Bight terrace. 


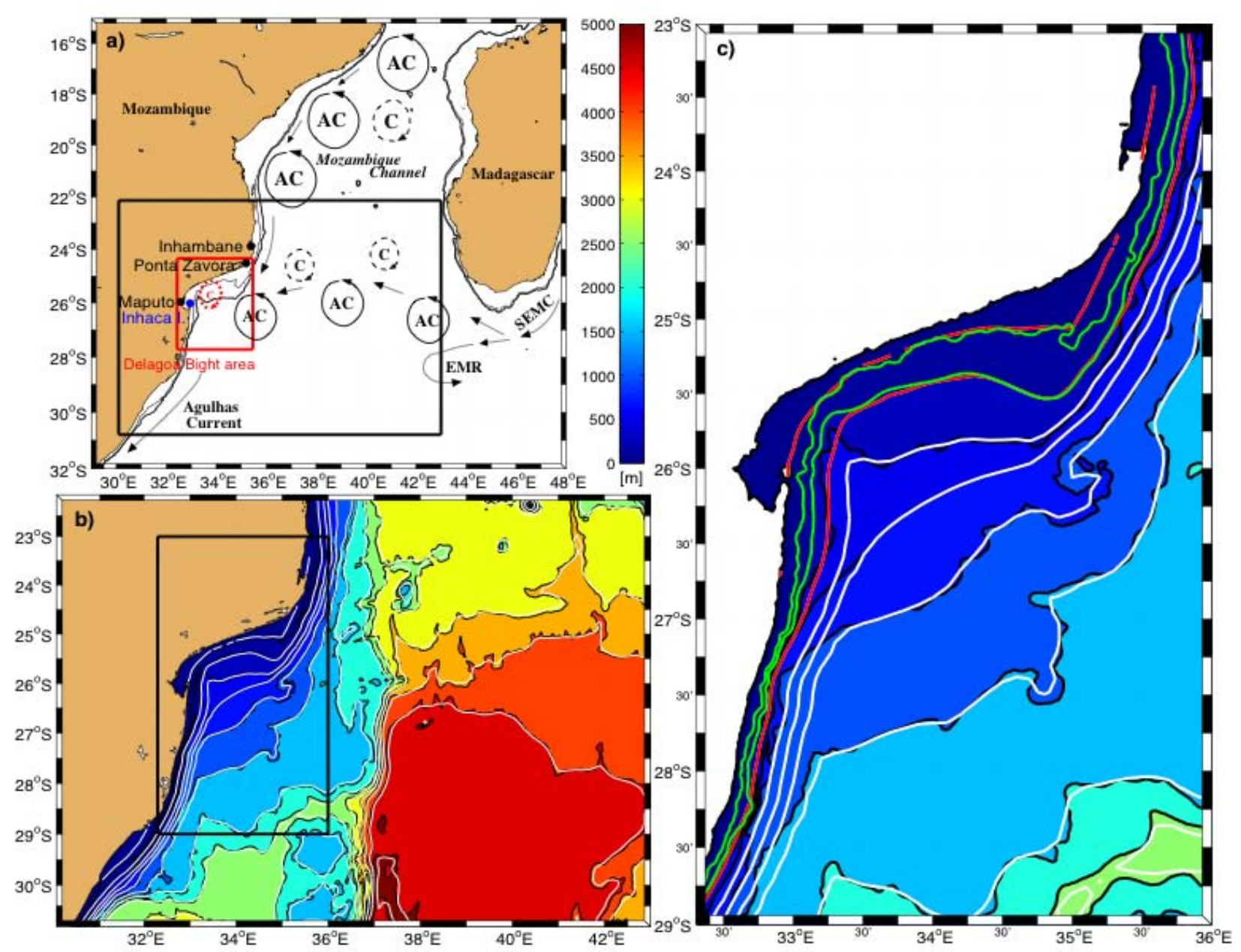

Figure 1: (a) General schematic of the circulation in the area (following Hancke et al., 2014, their figure 1). The thick black lines represents the ocean model domain. (b) Raw bathymetry (interpolation of Gebco1 dataset on the model grid) in colour shading and black contours (100, 500, 1000, 2000, 3000, 4000 and 5000 isobaths), overlaid by the smoothed bathymetry in white contours for the same isobaths. (c) Raw bathymetry for the Delagoa Bight region in colour shading and black contours (except 100 and 300m in green) overlaid by the smoothed bathymetry in white contours (except 100 and $300 \mathrm{~m}$ in red).

For the open lateral boundaries and initial conditions, we used high frequency outputs (3-days average) from a larger regional simulation. This configuration encompasses the southwest Indian Ocean and reproduces the mesoscale dynamics in the Mozambique Channel [Halo et al., 2014a; 2014b]. The model (hereafter ROMSSWIM) is forced at the surface by a monthly climatology of heat, freshwater fluxes and wind-stresses derived from the COADS $1 / 2^{\circ}$ resolution data [da Silva et al., 1994]. Model outputs (3 days-averaged) are analysed from year 3 to year 10 after the model reached its dynamical equilibrium. 
The option chosen at the boundary conditions allows incoming eddies from the Mozambique Channel which has been shown, though previous experiments, to be key in obtaining a realistic circulation in the study area. This illustrates the importance of non-local eddy forcing in this area. In particular, anticyclones dominate in the region and provide an essential source of potential vorticity in the nearshore regions in which they can propagate for weeks.

\subsection{Observational datasets used for comparisons}

Model surface dynamics are evaluated against sea surface height (SSH) and surface geostrophic currents derived from maps of absolute dynamic topography (MADT) produced by Ssalto/Duacs (DUACS 2014), and distributed by AVISO, with support from CNES (http://aviso.oceanobs.com/duacs/). The data were "Delayed Time" "all sat merged" global daily absolute dynamic topography on a 1/4 grid from January 1993 through May 2014 that combine sea level anomaly (MSLA) observations with a new mean dynamic topography [MDT_CNESCLS13, Rio et al., 2014]. The "all sat merged" data consist of data set from up to four satellites, using all the available missions at a given time. Here we chose the 2001-2008 period where at least 3 satellites were available at the same time from the Topex/Poseidon, ERS-2, Jason-1\&2, Envisat and GFO missions. In order to compare with model outputs averaged every 3 days, we extracted altimetry observations at the same frequency. Besides SSH data, AVISO provided an estimation of the error for MSLA and MDT separately. On average for 2001-2008, the mean MSLA error is $2.78 \pm 0.52 \mathrm{~cm}$ for our domain of interest. It is locally minimal in the Delagoa Bight area (1.5-2 cm, not shown). Errors in the MDT are around $2-4 \mathrm{~cm}$ in Delagoa Bight and are maximum in the western boundary current (greater than $6 \mathrm{~cm}$ near $30^{\circ} \mathrm{S}$, not shown).

Model sea surface temperature (SST) is compared to Pathfinder SST, a monthly climatology gridded at $9.28 \mathrm{~km}$ resolution of satellite SST derived from the NOAA AVHRR (Advanced Very High Resolution Radiometer) sensor from 1985 to 1997 [Casey and Cornillon, 1999].

\subsection{Geostrophic velocities and eddy kinetic energy}

The same methodology is applied to calculate EKE from modelled SSH or from AVISO MADT (both 3day averaged). The zonal (u) and meridional (v) components of the geostrophic velocities are derived from $\mathrm{SSH}$ through $u=-\frac{g}{f} \frac{\partial \eta}{\partial y}$ and $v=\frac{g}{f} \frac{\partial \eta}{\partial x}$ where $\mathrm{g}$ is gravity, $\mathrm{f}$ is Coriolis parameter and $\eta$ is $\mathrm{SSH}$. As suggest by Arbic et 
al. [2012] we used a seven-point stencil centred difference to estimate the derivatives. It contributes by reducing the impact of the anisotropy introduced by the Cartesian $1 / 4^{\circ}$ grid resolution. Eddy kinetic energy (EKE) is calculated from SSH-derived geostrophic velocities. EKE is defined as $\frac{1}{2}\left(u^{\prime 2}+v^{\prime 2}\right)$, where $u^{\prime}=u-\bar{u}$ and $v^{\prime}=v-\bar{v} ; \bar{u}$ and $\bar{v}$ being the temporal mean over the whole period.

\subsection{Composite analysis}

The DBLE is not fully stationary and can appear or disappear in response to the dynamics of the adjacent flow [Lamont et al., 2010]. To describe the main characteristics of the DBLE, two composites are created. The existence of a local minimum in $\mathrm{SSH}$ (the centre of the cyclonic eddy) located in a $0.5^{\circ} \times 0.5^{\circ}$ box centred in the middle of the Delagoa Bight (i.e. $26^{\circ} \mathrm{S}-34^{\circ} \mathrm{E}$ ) is our criterion to define the presence of a DBLE. This criterion for DBLE presence is designed to capture cyclonic eddies that remain in the Delagoa Bight. Those cyclonic eddies passing through this area which are not stationary or generated locally are excluded. Then 3-day averaged outputs of modelled SSH and AVISO MADT are carefully analysed to identify all situations that respect the criterion for presence of a DBLE. A similar analysis is conducted to extract all the situations which indicate the absence of cyclonic circulation (stationary DBLE and transient features are excluded) in the same region. Finally, composites in the presence (or absence) of DBLEs are constructed, as well as the associated time series.

\subsection{Eddy detection and tracking system}

In addition, an automated eddy detection and tracking system is used to characterise the eddy dynamics in the Delagoa Bight region. The eddy detection algorithm combines both geometric and dynamical properties to detect the eddies from SSH [Halo et al., 2014a,b]. With this method, an eddy consists of a closed contour of SSH associated with a negative Okubo-Weiss parameter [Okubo, 1970; Weiss, 1991], resulting in a more robust detection [Halo et al., 2014a,b]. This combination of methods results in a minimum of tuneable parameters with the intervals between the $\mathrm{SSH}$ closed contours set to $2 \mathrm{~cm}$ and the maximum SSH closed loop diameter set to $600 \mathrm{~km}$ to exclude gyre-scale features.

To track eddies in time, the system uses the method proposed by Penven et al. [2005], in which an eddy detected in a given frame is the same as an eddy detected in the subsequent frame if a generalised distance $X_{e 1, e 2}$ in a non-dimensional property space is minimum. 
$X_{e 1, e 2}=\sqrt{\left(\left(\Delta X / X_{0}\right)^{2}+\left(\Delta R / R_{0}\right)^{2}+\left(\Delta \xi / \xi_{0}\right)^{2}\right)}$ where $\Delta \mathrm{X}$ is the spatial distance between the eddy centres e1 and $\mathrm{e} 2, \Delta \mathrm{R}$ is the variation of diameter, $\Delta \xi$ is the variation of vorticity, $\mathrm{X}_{0}$ is a characteristic length scale $(100 \mathrm{~km})$, $R_{0}$ is a characteristic radius $(50 \mathrm{~km})$, and $\xi_{0}$ is a characteristic vorticity $\left(10^{-5} \mathrm{~s}^{-1}\right) . X_{\mathrm{e} 1, \mathrm{e} 2}$ is considered infinite if there is a change of sign in vorticity to ensure that no cyclone becomes an anticyclone (i.e., an eddy should preserve its polarity). All the parameters are the same for all tracking experiments.

\section{Results}

\subsection{Modelled regional mean ocean circulation, SST and eddy energy}

To describe the mean characteristics of the large scale flow in Delagoa Bight and surroundings, the mean dynamic topography is presented in Figure 2 for AVISO and ROMS-SWIM. For AVISO, a mean southward current can be seen flowing southward along the African coast from the north of the domain. Just offshore of Delagoa Bight, it merges with a mean westward zonal flow extending from the southern tip of Madagascar. This extension of the South Madagascar current is wide $(\sim 200 \mathrm{~km})$ and meanders, possibly due to a high level of mesoscale turbulence. The merger results in the Agulhas Current flowing southward along the coast from about $27^{\circ} \mathrm{S}$. ROMS-SWIM reproduces the merger between a southward flow along the African coast and a wide westward South Madagascar Current extension, resulting in a realistic surface expression of the northern part of the Agulhas Current.
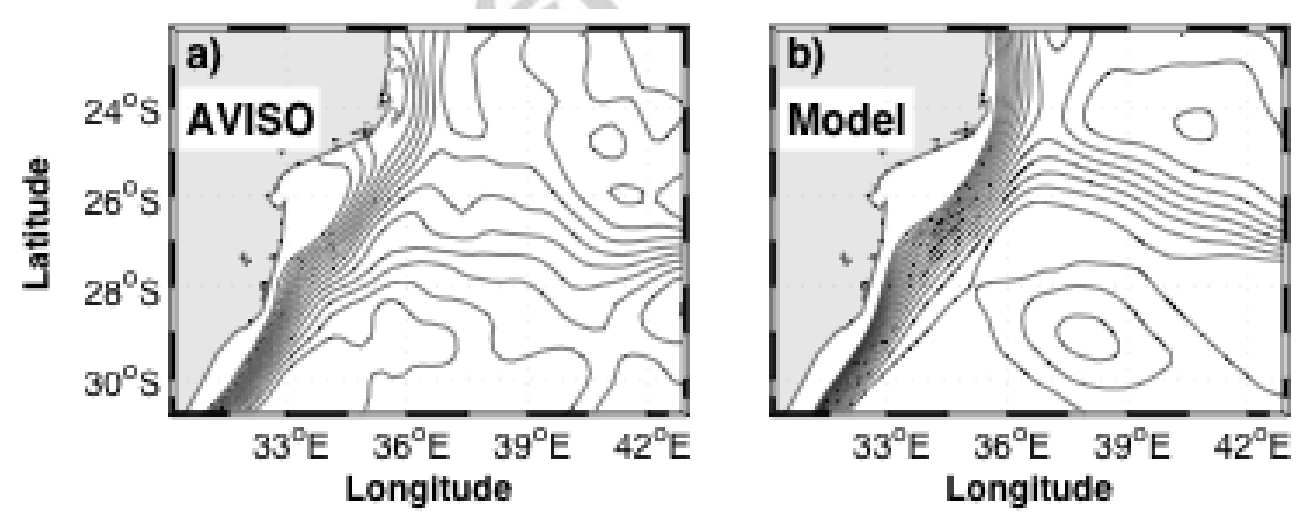

Figure 2: Mean sea surface height for (a) AVISO mean dynamic topography and (b) ROMS-SWIM (contour interval is $3 \mathrm{~cm}$ ).

On the northern side of the bight, between $23^{\circ} \mathrm{S}$ and $24^{\circ} \mathrm{S}$, the SSH isolines (Figure 2) are closer to each other 
for ROMS-SWIM compared to AVISO. Here the coastal surface mean southward flow is stronger for ROMSSWIM than for AVISO. Because of the turbulent nature of the flow in the region, the lack of direct (long term) current observations, and the known problem of representation of coastal currents in mean dynamic topography, it is difficult to assess the realism of this representation of this along coast southward current by ROMS-SWIM (see Appendix). ROMS-SWIM also differs slightly from AVISO in the mean pathway of the South Madagascar Current extension. It is narrower and less affected by meanders in ROMS-SWIM, resulting in a quasi-straight flow in a west to northwest direction. This behaviour could be constrained by the eastern boundary condition as a similar pathway is observed in the larger simulation used as boundary conditions for our model configuration [see Figure 2 in Halo et al., 2014b].

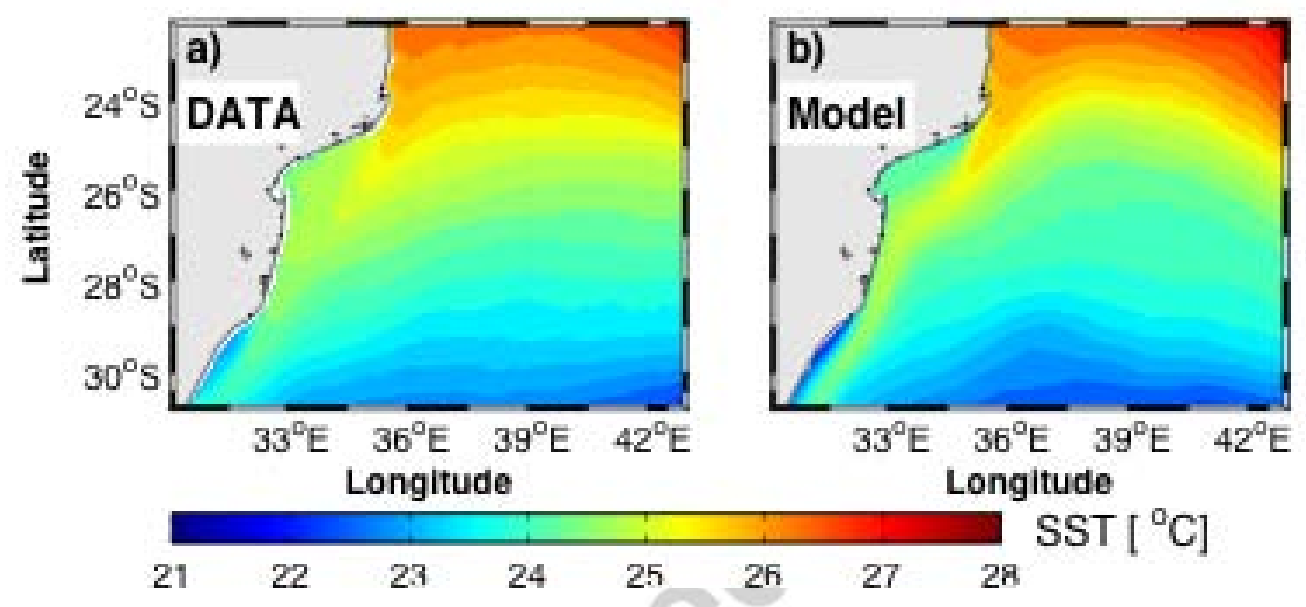

Figure 3: Mean sea surface temperature $\left[{ }^{\circ} \mathrm{C}\right]$ for (a) Pathfinder and (b) ROMS-SWIM.

Annual mean SST from Pathfinder and ROMS-SWIM are presented in Figure 3. Both ROMS-SWIM and Pathfinder indicate the narrow paths of a southward current along the southern Mozambican coast followed by the Agulhas current, and the associated poleward transport of warmer water masses. The wide path of the South Madagascar Current extension can also be seen in SST, resulting in a slant of the SST contours in a northwest direction across the eastern half of the southern Mozambique Channel in ROMS-SWIM. There is agreement between Pathfinder and ROMS-SWIM in showing cooler mean SST in Delagoa Bight. In the Bight, surface water varies in ROMS-SWIM between $21.5^{\circ} \mathrm{C}$ in winter to $28^{\circ} \mathrm{C}$ in summer (not shown) in agreement with observations [Kyewalyanga et al., 2007; Barlow et al., 2008; Lamont et al., 2010].

In general, the mean ROMS-SWIM thermohaline properties coincide with observations as illustrated in late 
March of year 8 when an anticyclonic eddy was present at $24^{\circ} \mathrm{S}$ (Figure $4 a$ ). This particular situation is close to that observed at the end of March 2000 during the ACSEX 1 cruise and described by de Ruijter et al. [2002, their figure 1]. As shown by LADCP observations [de Ruijter et al., 2002; their figure 2b] the meridional velocity section indicates the presence of an anticyclone centred at around 200-250 km offshore (Figure 4c) and penetrating down to the bottom with velocities over the upper $200 \mathrm{~m}$ larger than $60 \mathrm{~cm} \mathrm{~s}^{-1}$. Below $1500 \mathrm{~m}$, an equatorward undercurrent flows along the continental slope but it is deeper and weaker than observed. As indicated by the $T-S$ diagram (Figure $4 \mathrm{~b}$ ), the model is able to reproduce the different water masses compared to the WOA and to ACSEX observations [de Ruijter et al., 2002; red dots on their figure 4] but an excessive mixing seems to occur in the model at depth. This results in an overestimate of the salinity of Antarctic Intermediate Water (characterised by salinity lower than $34.6 \mathrm{psu}$ ) and an underestimate of the salinity of SubTropical Water (characterised by salinity greater than $35.4 \mathrm{psu}$ ) in the model compared to observations. Nevertheless, the model is able to reproduce the sub-surface salinity maximum around $200 \mathrm{~m}$ depth as well as a salinity minimum at 1500 m depth (Figure 4d), although slightly deeper than observed [de Ruijter et al., 2002; their figure 5].

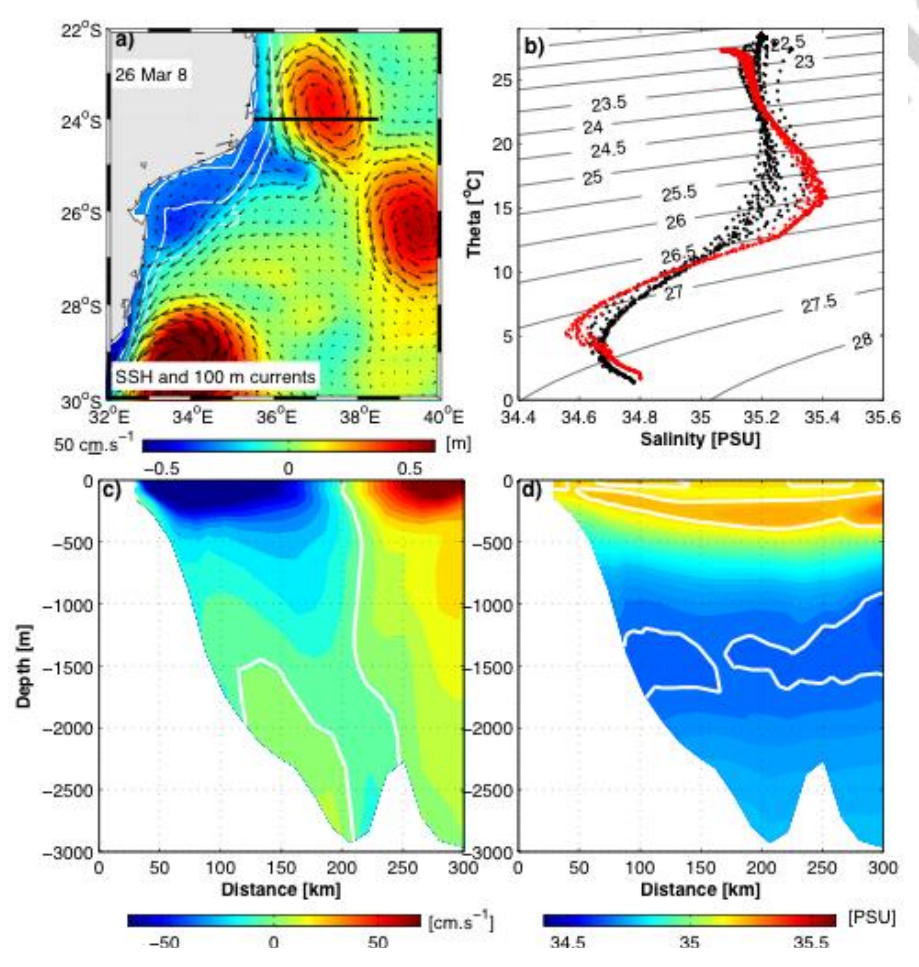

Figure 4: (a) Modelled SSH and currents at $100 \mathrm{~m}$ depth showing the presence of an anticyclone near $24^{\circ} \mathrm{S}$ in late March of year 8. (b) Temperature-salinity diagram along a section at $24^{\circ} \mathrm{S}\left(35-38.5^{\circ} \mathrm{E}\right)$ from model output (black dots) and March climatological data from WOA (red dots). (c) Vertical section of modelled meridional 
velocity along the section (white contours indicate the zero isotach). (d) Vertical section of modelled salinity along the section (white contours indicate 34.68 and 35.2 psu isohalines).

Another minor bias is observed in the model over the continental terrace of Delagoa Bight; the salinity maximum ( $\mathrm{S}>35.2 \mathrm{psu}$ ) at $200 \mathrm{~m}$ depth which is the nearshore signature in salinity of the southward flow in the Mozambique Channel [Lutjeharms and da Silva, 1988] is not visible in the model westward of $35^{\circ} \mathrm{E}$ (not shown).

The mean surface eddy kinetic energy (EKE), which is a common measure of mesoscale activity in the ocean is presented for AVISO and ROMS-SWIM in Figure 5. For AVISO, high values of EKE (above $1000 \mathrm{~cm}^{2} \mathrm{~s}^{-2}$ ) underline the two major pathways of the eddies coming from the Mozambique Channel (most importantly, the Mozambique Channel rings [Halo et al., 2014a]) and from south of Madagascar. As shown in the mean circulation in Figure 2, the two pathways merge offshore of Delagoa Bight. This merging appears associated with a local maximum in EKE for the model and a more diffuse pattern for AVISO. Lower values (about $300 \mathrm{~cm}^{2} \mathrm{~s}^{-2}$ ) are found in the northern Agulhas Current region. Values of the order of $100 \mathrm{~cm}^{2} \mathrm{~s}^{-2}$ can be seen in Delagoa Bight. ROMS-SWIM is able to reproduce reasonably the 2 major eddy pathways with EKE values comparable to observations. Interestingly, the eddy dissipation/transfer in ROMS-SWIM appears to be less efficient, resulting in a higher EKE in the Agulhas current region compared to AVISO. Nevertheless, ROMS-SWIM produces EKE values comparable to AVISO in Delagoa Bight, the region of interest.

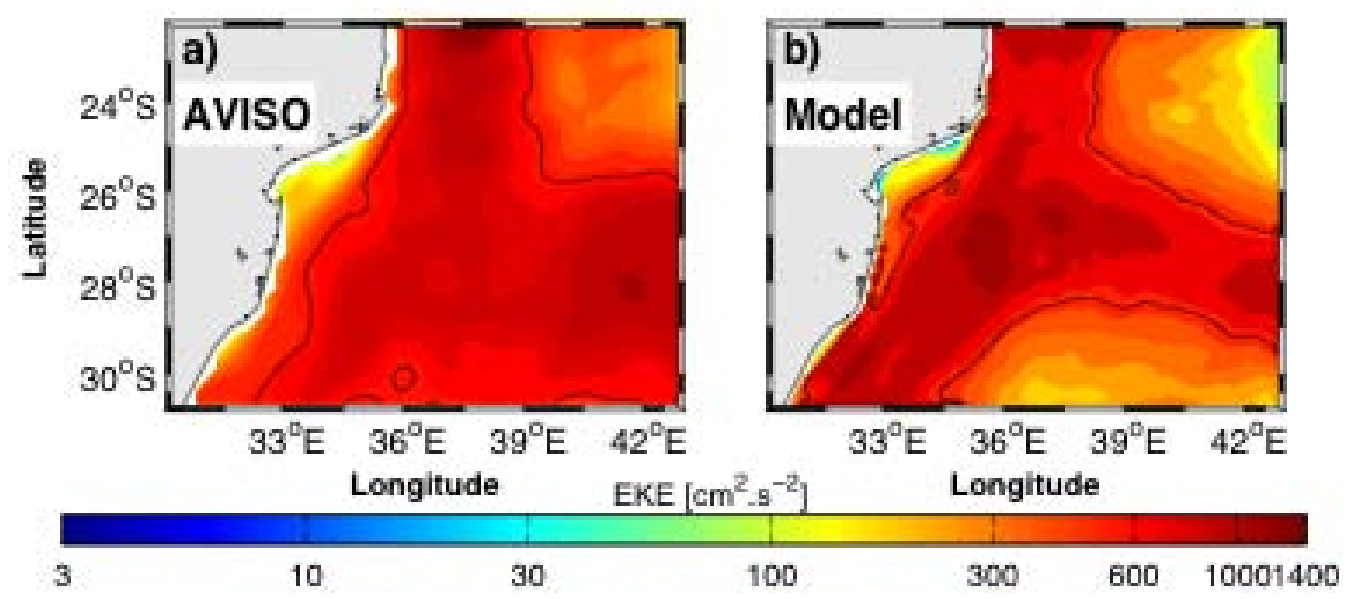

Figure 5: Mean eddy kinetic energy for (a) AVISO and (b) ROMS-SWIM (black contours indicate $600 \mathrm{~cm}^{2} \mathrm{~s}^{-2}$ isolines). 


\subsection{Delagoa Bight lee eddies}

As described in section 2.5, we identify the snapshots when DBLE is present in both model and AVISO datasets. The number of all these events divided by the total number of snapshots gives the overall percentage of occurrence of the DBLE, which is very similar for AVISO (23.0\%) and ROMS-SWIM (22.4 \%).

The number of occurrences of DBLE is accounted for each month and a climatology of these monthly occurrences is created to identify an eventual seasonality in DBLE presence. Monthly mean occurrences of DBLE vary between 5 and $13 \%$ in AVISO and between 2 and $17 \%$ for ROMS-SWIM (Figure 6). Because the investigated time period is limited to 8 years, Figure 6 also presents the associated standard deviation for DBLE occurrence for each month (i.e. over 8 years). If DBLE occurrence were the same in all months, then the climatological occurrence for each month should be $100 / 12=8.3 \%$. This value stands within mean \pm std for each month in both AVISO and ROMS-SWIM (except for the month of November in the model output, which remains unexplained), suggesting that the DBLE occurrence is not significantly different from one month to another. Hence, there is no indication of seasonality in DBLE occurrences. Because of this lack of seasonality, the composite of snapshots in presence of DBLE combines 3-day averaged outputs irrespective of their associated month. The composite corresponding to absence of DBLE is obtained similarly by ignoring seasonality.

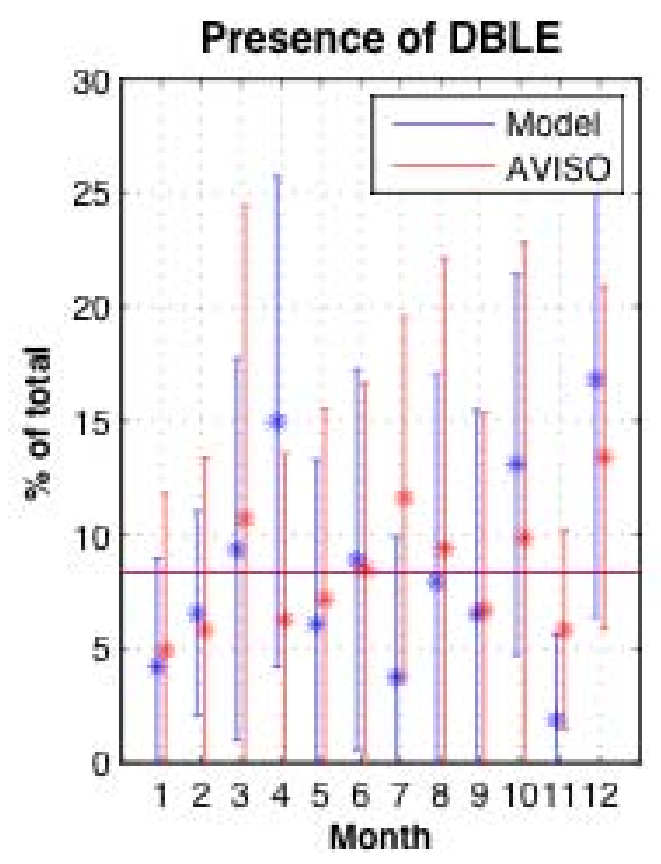

Figure 6: Monthly climatology of DBLE in model outputs (blue) and AVISO (red): monthly mean occurrences normalised by the total number of occurrences (asterisks) and standard deviation calculated over the 8-year 
study period for each data set (vertical lines). The horizontal line provides the percent of occurrences assuming all months have the same number of events.

The composites of events when a DBLE is present and when it is absent in ROMS-SWIM are compared for SSH and associated geostrophic velocities (Figure 7a and e), for temperature at $100 \mathrm{~m}$ depth (Figure 7c and g) and for salinity at $100 \mathrm{~m}$ depth (Figure $7 \mathrm{~d}$ and $\mathrm{h}$ ). The composites are also illustrated in AVISO for SSH and associated geostrophic velocities (Figure 7b and f), and in ROMS-SWIM for the vertical structure of temperature, salinity and circulation through the Delagoa Bight (Figure 8). A statistical test (Student t-test with $95 \%$ significance level) is included in these diagnostics to identify whether and where the two composites, i.e. with and without DBLE, are significantly different from each other (for each variable that is plotted, see legend of Figures 7 and 8). Although there are some points where the composite of present DBLE is not significantly different from that of absent DBLE, mostly offshore, the differences are significant for the circulation and thermohaline structure in the Delagoa Bight, which is the focus of this particular analysis.

The DBLE is clearly visible in model SSH and geostrophic currents (Figure 7a), $100 \mathrm{~m}$ temperature (Figure 7c) and $100 \mathrm{~m}$ salinity (Figure $7 \mathrm{~d}$ ). The eddy is centred around $26^{\circ} \mathrm{S}-33.8^{\circ} \mathrm{E}$ and covers the entire Bight area with a radius varying approximately from 50 to $75 \mathrm{~km}$. It is associated with colder and fresher waters in its core. The 17 ${ }^{\circ} \mathrm{C}$ and $18{ }^{\circ} \mathrm{C}$ isotherms are concentric and capture the lee eddy, as well as the isohalines below 35.2 psu. The presence of the eddy is associated with a northward current along Inhaca Island and Maputo Bay around $26^{\circ} \mathrm{S}$. In the absence of a DBLE, a southward flowing mean boundary current tends to follow the $1000 \mathrm{~m}$ isobath over a width of $100 \mathrm{~km}$ (Figure 7e). It appears stronger than when the DBLE is present. An offshore anticyclonic recirculation in the southern part of the no DBLE composite could be related to the presence of large anticyclones (such as Mozambique Channel rings) affecting the behaviour of DBLE. Note that even in the state without a DBLE, a bulge of cold $\left(<18^{\circ} \mathrm{C}\right)$ and fresh $(<35.2 \mathrm{psu})$ water remains present inshore in the Bight (Figure $7 \mathrm{~g}$ and $\mathrm{h}$ ) in accordance with the prevailing cyclonic conditions there. The northern region of the Bight shows weak currents.

The DBLE has similar structure and intensity in the AVISO composite (Figure 7b) except for a southwestward shift of the position of the eddy centre compared to that in the model. This discrepancy could be due to the known limitations of satellite observations near the coast. In the case of absence of DBLE, the differences 
between the model and AVISO composites are more obvious (Figure 7e vs 7f). First, a residual small cyclonic circulation is present close to the coast in the AVISO composite mainly due to a similar circulation in the MDT product centred near $\left(26.5^{\circ} \mathrm{S}, 33.25^{\circ} \mathrm{E}\right.$ ) (not shown) that may be due to errors in the AVISO product (see also the discussion on MDT error on section 2.3). Second, the large anticyclonic structure seen in the model composite (Figure 7e) is absent from AVISO. However, a similar albeit weaker structure is present further south (centred at $30.5^{\circ} \mathrm{S}, 34^{\circ} \mathrm{E}$, not shown; note that this structure is distinct from the high sea-level wedge visible in Figure $7 \mathrm{f}$ which is in an area where DBLE-no DBLE differences are not statistically significant). Semi-permanent features are inherently complex to reproduce in models [Centurioni et al., 2006] and this bias may arise from a variety of reasons. 

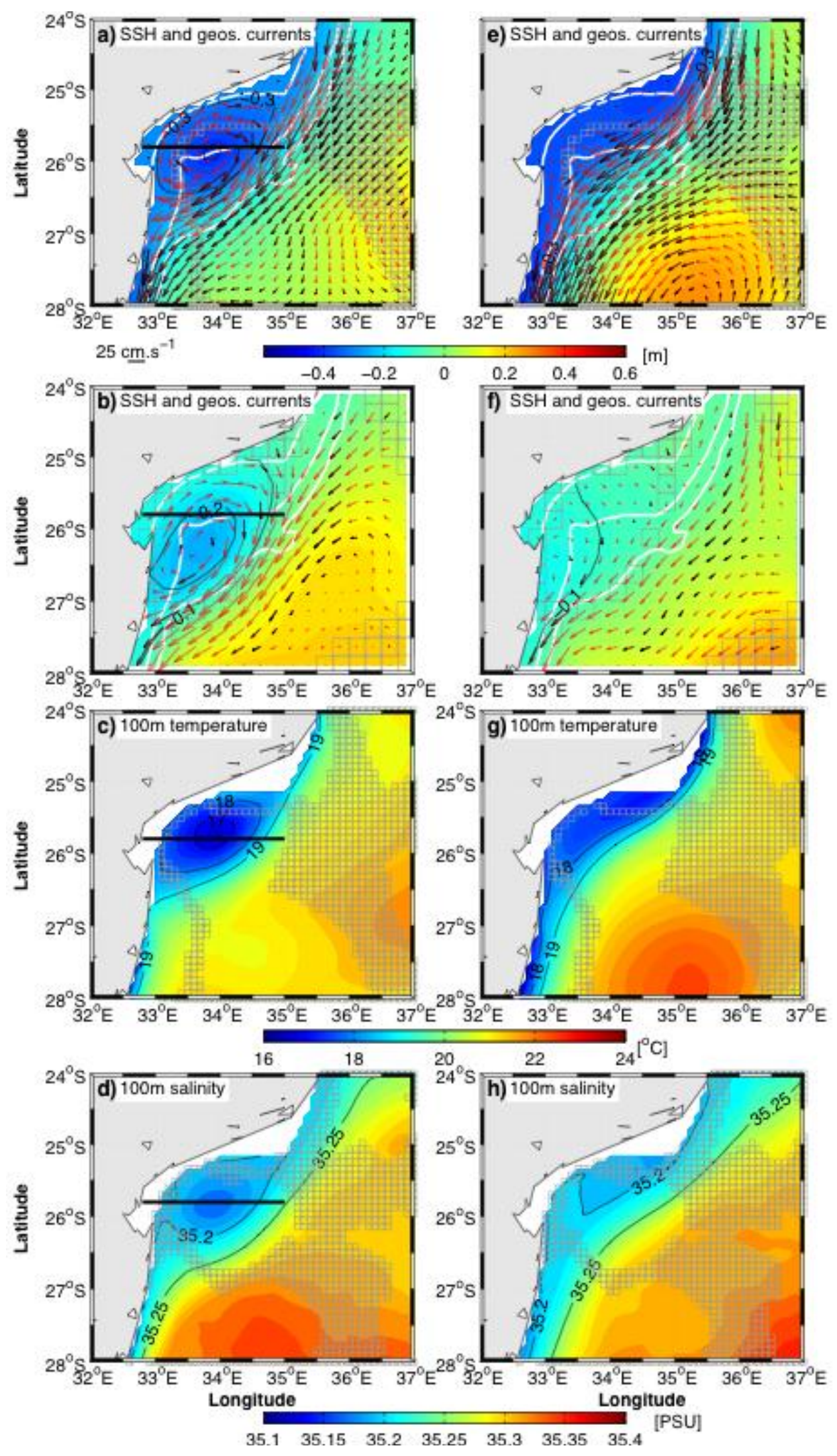

Figure 7: 3-days composites, for model SSH and geostrophic currents (a and e), for AVISO SSH and geostrophic currents ( $b$ and f), model $100 \mathrm{~m}$ temperature (c and g) and $100 \mathrm{~m}$ salinity ( $\mathrm{d}$ and $\mathrm{h}$ ), in the case of the presence 
of a DBLE (left) or the absence of a DBLE (right). 100, 500 and 1000 isobaths are represented by white lines on a), b), e) and f). Grey symbols in $\mathrm{SSH}$, temperature and salinity indicate where the difference in between the two composites is not significant (according to a Student t-test with $95 \%$ significant level). Composite currents shown in red are significantly different in between the two composites, and shown in black otherwise.
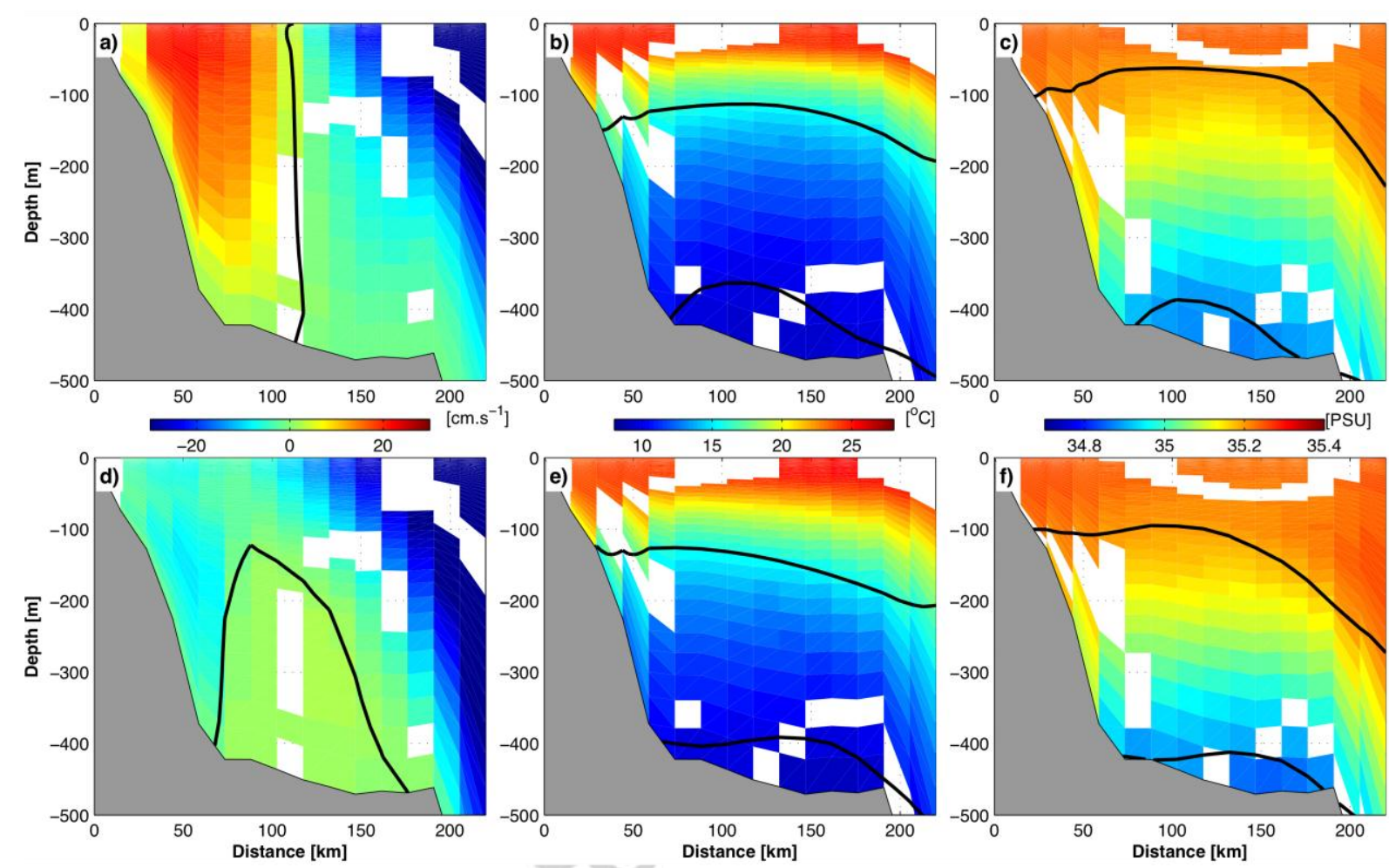

Figure 8: Vertical sections of composites of modelled meridional currents ( $a$ and d), temperature (b and e) and salinity ( $c$ and f), across the Delagoa Bight, in the case of the presence (top) or absence (bottom) of a DBLE. Black lines indicate the zero isotach ( $a$ and $c$ ), 10 and $16{ }^{\circ} \mathrm{C}$ isotherms (b and e) and 34.9 and 35.2 psu isohalines (c and f). White shading in meridional current, temperature and salinity indicate where the difference in between the two composites is not significant (according to a Student t-test with $95 \%$ significant level).

With regard to the vertical structure in the Delagoa Bight, the presence of the DBLE is associated with a doming in temperature (Figure 8b) and salinity (Figure 8c) that is particularly marked below $250 \mathrm{~m}$ as observed by Lutjeharms and da Silva [1988] and Lamont et al. [2010]. Deeper than $400 \mathrm{~m}$, the water mass of the eddy is characterised by temperature lower than $10^{\circ} \mathrm{C}$ and salinity lower than $34.9 \mathrm{psu}$. In the observations of Lutjeharms and da Silva [1988, their Figure 2] or Lamont et al. [2010, their Figure 2] these values are typically found at lower depths $\sim 300 \mathrm{~m}$. This discrepancy could be attributed to the fact that the waters below $400 \mathrm{~m}$ are 
fed by upwelled AAIW situated deeper in our model results. Although the doming is less marked, the thermohaline structure is relatively similar in the no DBLE composite (Figure $8 e$ and f) but still the differences in between the two composite states are statistically significant.

The differences in meridional currents across the Delagoa Bight in presence vs absence of DBLE (Figure 8a and d) are substantial. The signature of the eddy in meridional velocities is clear, and extends from surface down to bottom in the Bight. The eddy velocities are surface intensified $\left(\sim \pm 20 \mathrm{~cm} \mathrm{~s}^{-1}\right.$ or more in the first $\left.100 \mathrm{~m}\right)$ and progressively diminish toward zero with depth. The cyclonic circulation is evident with a sign change in the current about $100 \mathrm{~km}$ away from the coastline (the zero $\mathrm{v}$ isoline shows a very slight tilt). The coastal countercurrent forming the inshore part of the eddy [Lutjeharms and da Silva, 1988; Lamont et al., 2010] is marked by northward currents that remain around $20 \mathrm{~cm} \mathrm{~s}^{-1}$ a few grid points from the shore. The offshore part of the eddy is characterised by a southward flow of more than $50 \mathrm{~cm} \mathrm{~s}^{-1}$ that reflects the influence of a southward current along the Mozambican coast. This difference between eastward and westward flows around the eddy has been shown by Lamont et al. [2010] using surface drifter data. When the DBLE is absent, the velocities on the shelf are weak (Figure 8d) without any coastal countercurrent. A southward flow, stronger than in the case of DBLE is located on the shelf break, 150 to $200 \mathrm{~km}$ offshore. A weak northward subsurface current occupies the region over the shelf and reflects the veering of the southward current following the $500 \mathrm{~m}$ isobath that delimits the terrace (Figure 8d).

Although Figures 7 and 8 show substantial (and significant) changes in the Bight depending on the presence of DBLEs, the effects of the offshore circulation on the DBLE generation remains unclear. A careful examination of sequences of instantaneous vorticity maps (Figure 9) provides some useful indications about the links between DBLE onset/presence and the state of the surrounding dynamical environment. Indeed, the presence of a DBLE results from the flow tendency to produce cyclonic vorticity that can maintain itself within the Bight over several days. On the time and space scales that we are interested in, there are two main potential processes responsible for vorticity changes along water parcel trajectories: namely, the adiabatic stretching and squashing of water columns [Cushman-Roisin, 1994], and the frictional processes occurring on the inshore side of the boundary current [D'Asaro, 1988]. 

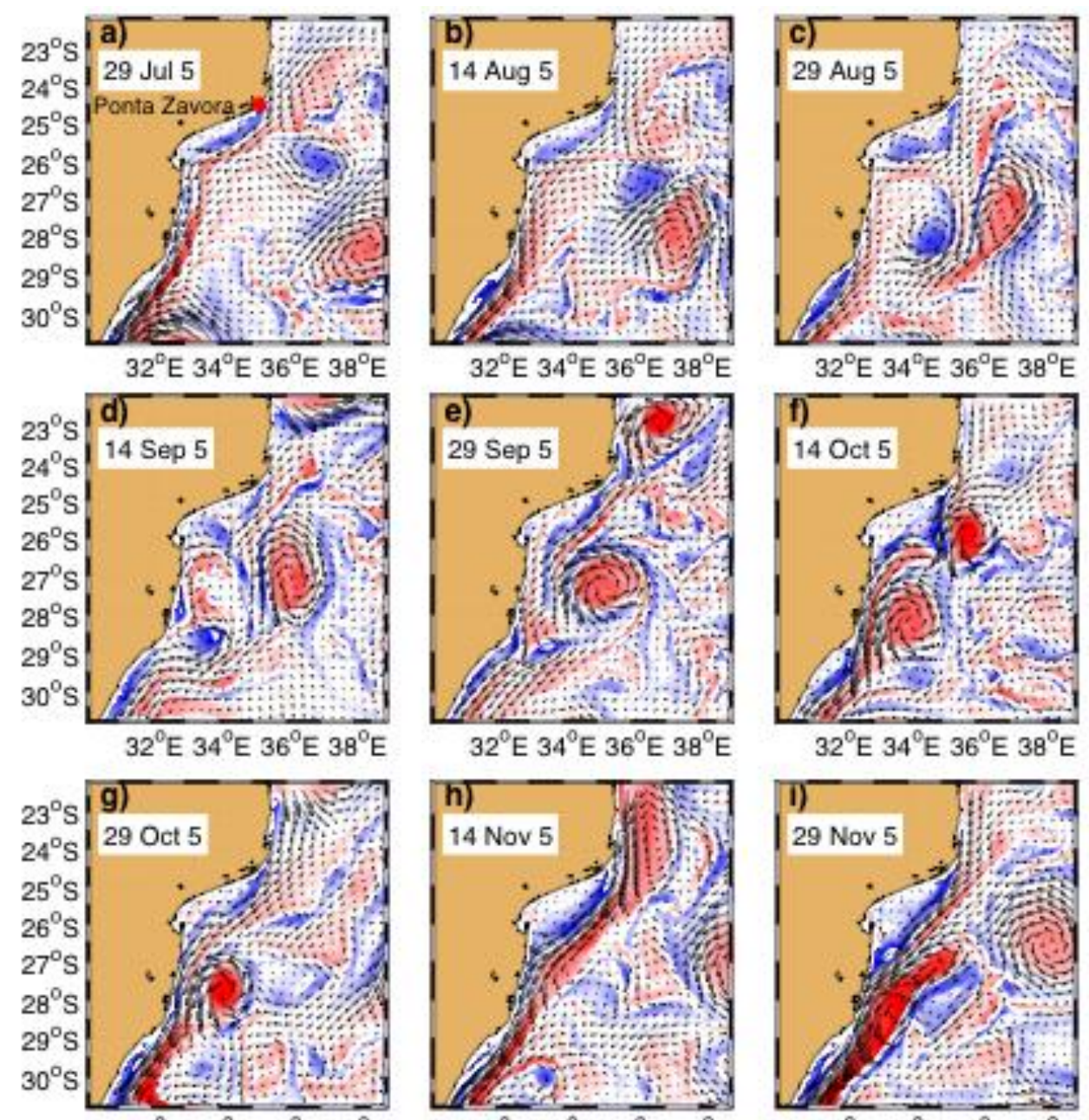

$32^{\circ} \mathrm{E} 34^{\circ} \mathrm{E} 36^{\circ} \mathrm{E} 38^{\circ} \mathrm{E}$
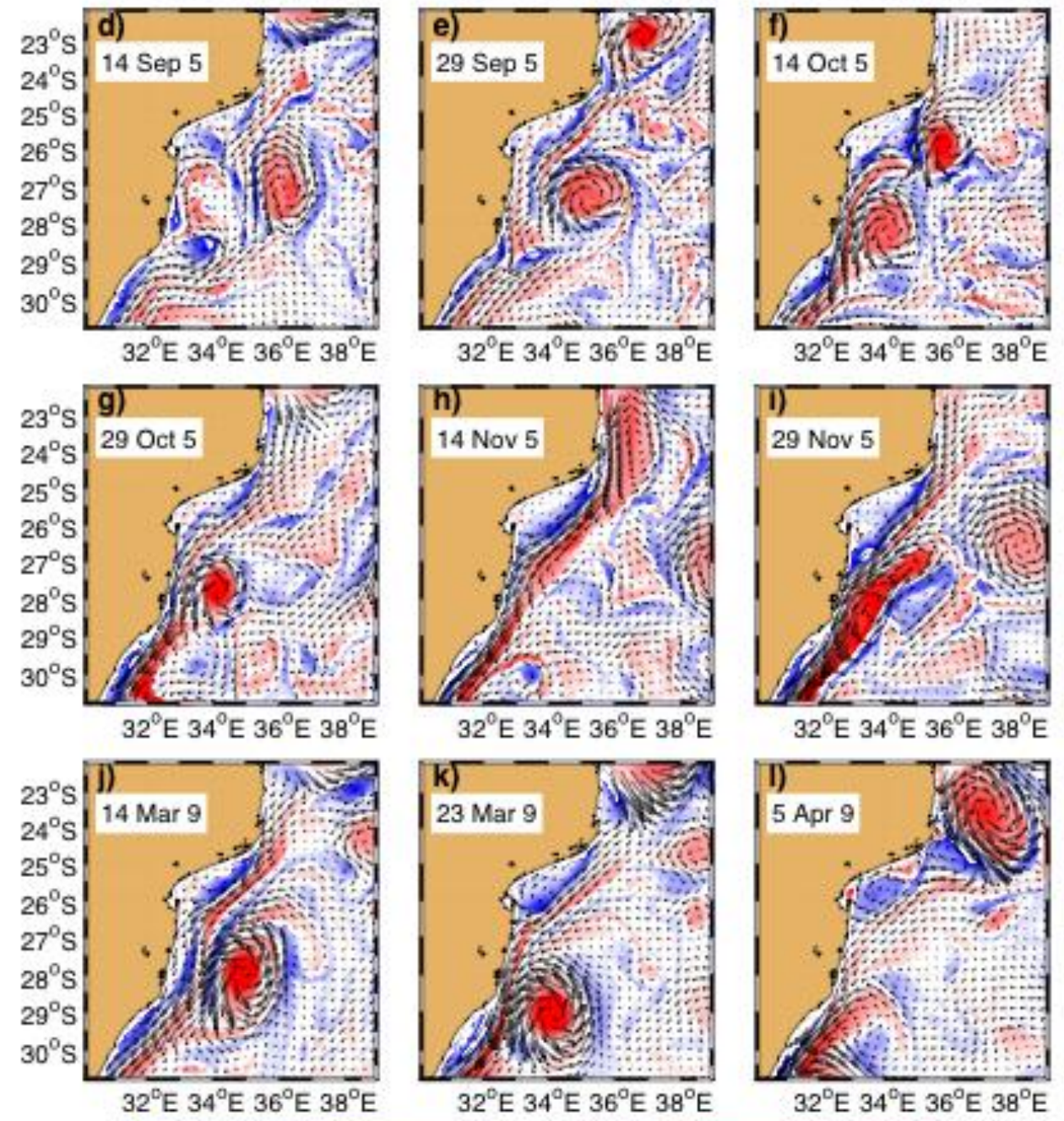

$32^{\circ} \mathrm{E} 34^{\circ} \mathrm{E} 36^{\circ} \mathrm{E} 38^{\circ} \mathrm{E}$

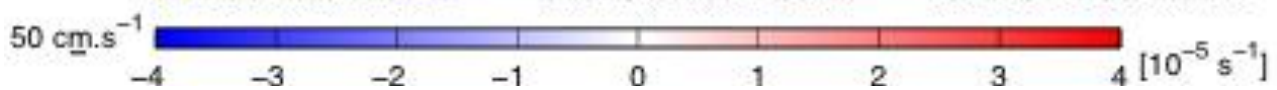

Figure 9: Simulated surface velocities overlaying surface relative vorticity map for 3-day averages between July,

29 and November, 29 of year 5 (panels a to i) and between March, 14 and April, 5 of year 9 (panels j to I). A Delagoa Bight eddy was present from August, 14 to September, 20 of year 5 and from March, 20 to April, 17 of year 9.

Most of the vorticity maps in Figure 9 (and more generally for the entire simulated period, not shown) exhibit an 
elongated patch of negative vorticity that has its origin near the Cape at Ponta Závora (this is particularly evident in panels $a, b$ and $h$ ) or more occasionally further upstream (panel e and $g$ ) and is advected southward by the dominant flow. Because negative vorticity appears in a localised area in conjunction with offshore advection of nearshore waters, vortex stretching is presumably the dominant process responsible for eddy generation (note that vortex stretching is consistent with the temperature and salinity sections on Figure $8 \mathrm{~b}$ and e). The patch of negative vorticity can remain within the Bight (Figure 9a), follow the outer slope (Figure 9h and i) or be wrapped around an offshore eddy and head south-eastward (Figure 9f) which will affect the flow conditions in the Bight. Based on this and other sequences we investigated, conditions favourable to the onset of the DBLE appear to be those when 1) mesoscale activity is some distance away from the Bight and, 2) the intensity of the southward current is weak or moderate. Those two conditions are satisfied for example on 29 Jul 5 (Figure 9a), 14 Aug 5 (Figure 9b) and 29 Aug 5 (Figure 9c), times when, or just before, a DBLE is visible. In contrast, when the coastal southward current is intense (hence condition 2 is not satisfied, see for example Figure $9 \mathrm{~h}$ and I and also in the no DBLE composite situation in Figure 7e), and/or mesoscale features are located too close to the Bight (hence condition 1 is not satisfied, see for example Figure $9 e$ and f), a DBLE is not present. Note that a substantial overlap may exist between conditions 1) and 2) because when mesoscale activity is some distance away from the Bight, currents in the region tend to be weaker.

A particular situation that frequently leads to robust DBLEs is associated with the approach of large anticyclones (positive vorticity) close to the coast in the latitudinal band of $27^{\circ} \mathrm{S}-29^{\circ} \mathrm{S}$. This situation (visible in Figure $9 \mathrm{~g}$ and j) frequently satisfies condition 1) and also condition 2) when the DBLE formation occurs (Figure 9k). On the other hand, other mesoscale structures present further north can prevent DBLE formation, as in Figure $9 \mathrm{~g}$ and $\mathrm{h}$, where a Mozambique Channel pulse leads to an intensified flow at the latitude of the Delagoa Bight (see the large positive vorticity elongated patch in Figure 9h).

Under favourable conditions comprising 1) and 2) the negative vorticity plume that originates from Ponta Závora is able to fill a large part of the Bight and take a more axisymmetric shape (Figure 9c and d). The formation of this axisymmetry and the subsequent fate of any formed DBLE must be sensitive to numerous processes including the image effect [Shi and Nof, 1994], interaction with the bathymetry, interaction with the turbulent offshore flow and the upstream conditions. The investigation of these processes is beyond the scope of the present study but we present below some statistics on DBLE characteristics and life cycle and also on eddies 
formed further north that may have an influence on DBLE formation.

The intermittent behaviour of the DBLE described by Lamont et al. [2010] is illustrated for ROMS-SWIM and AVISO using an eddy detection algorithm (see Material and methods). Cyclones generated in the black box shown in Figure 10 are considered for 8 years of model simulation and AVISO observations (2001 to 2008) in the derivation of the statistics.
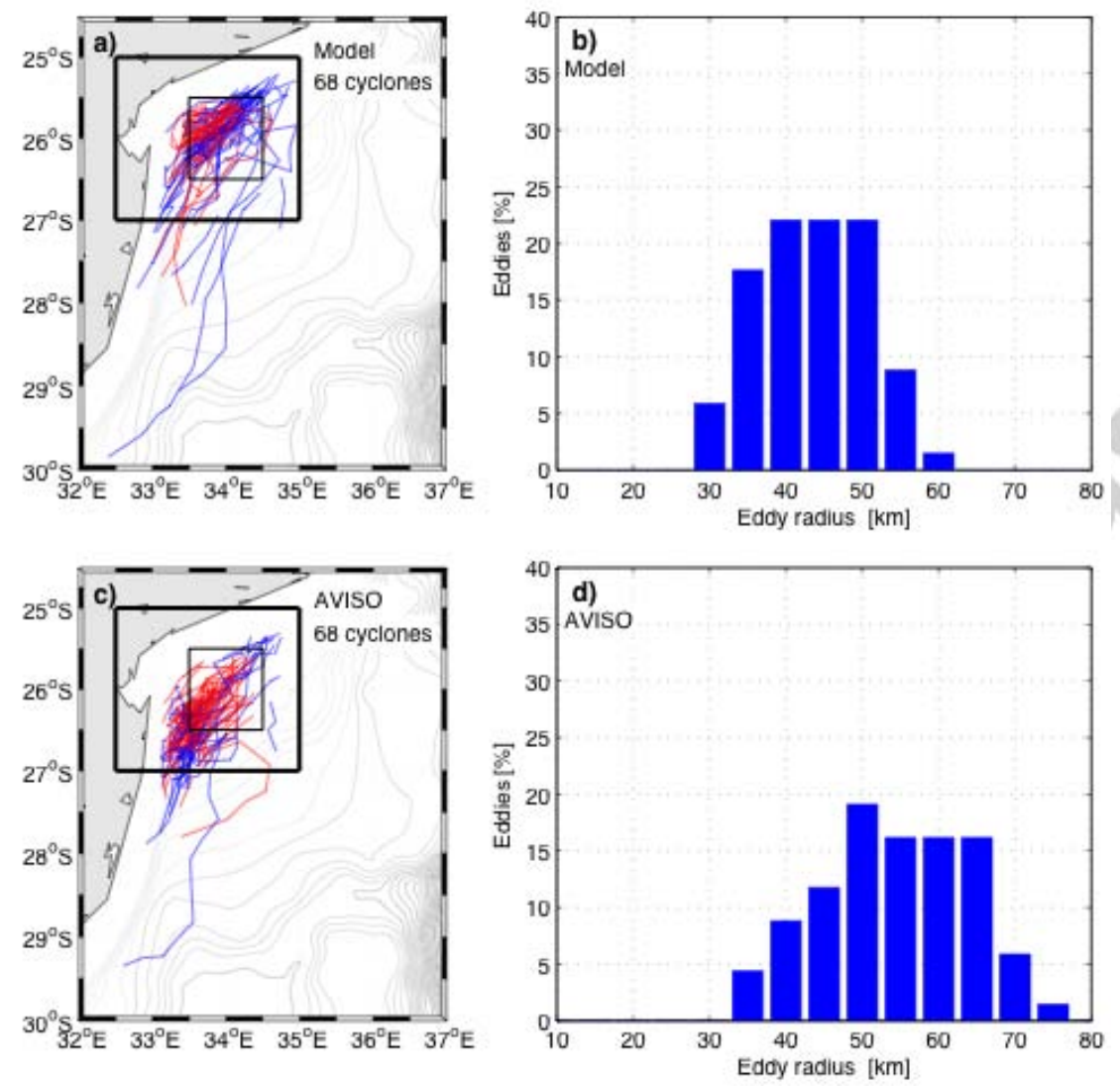

Figure 10: Trajectories (left) and radius distribution (right) of detected eddies in ROMS-SWIM (top) and in AVISO altimetry data (bottom). Tracks in blue are for cyclonic eddies initially detected in the Delagoa Bight region defined by the black thick line and tracks in red correspond to cyclonic eddies initially detected in the box [33.5$\left.34.5^{\circ} \mathrm{E} ; 25.5-26.5^{\circ} \mathrm{S}\right]$ defined by the black thin line.

68 eddies have been tracked in ROMS-SWIM with a mean diameter of about $87 \pm 14 \mathrm{~km}$ (Figure 10a and $\mathrm{b}$ and Table 1). They have a mean total life time of $23 \pm 15$ days in the Delagoa Bight region defined by the black box and a mean amplitude of $\mathrm{SSH}$ of $8 \pm 4 \mathrm{~cm}$. The older eddies persist for 63 days which is close to the 10 weeks estimate from observations by Lamont et al. [2010]. 


\begin{tabular}{|l|l|l|l|l|l|l|}
\hline DBLE & $\begin{array}{l}\text { Number } \\
\text { of eddies }\end{array}$ & $\begin{array}{l}\text { Diameter }[\mathrm{km}] \\
\text { mean }(\mathrm{std}) / \text { min-max }\end{array}$ & $\begin{array}{l}\text { Mean (std) } \\
\text { Life Time } \\
{[\text { days }]}\end{array}$ & $\begin{array}{l}\text { Mean (std) } \\
\text { Amplitude } \\
{[\mathrm{cm}]}\end{array}$ & $\begin{array}{l}\text { Presence in the } \\
\text { box [\%] }\end{array}$ & $\begin{array}{l}\text { Reach } \\
27 / 28^{\circ} \mathrm{S}[\%]\end{array}$ \\
\hline AVISO & 68 & $109(20) / 66-152$ & $25(21)$ & $11(4)$ & 57.8 & $29.4 / 1.5$ \\
\hline $\begin{array}{l}\text { AVISO } \\
\text { Small box }\end{array}$ & 36 & $115(19) / 66-152$ & $21(24)$ & $12(4)$ & 25.5 & \\
\hline Model & 68 & $87(14) / 61-120$ & $23(15)$ & $8(3)$ & 54.1 & $20.6 / 5.9$ \\
\hline $\begin{array}{l}\text { Model } \\
\text { Small box }\end{array}$ & 33 & $88(14) / 68-120$ & $18(15)$ & $8(3)$ & 20.5 & \\
\hline
\end{tabular}

Table 1: Summary of Delagoa Bight cyclonic eddy characteristics estimated from the tracking system

Using AVISO data, 68 eddies have also been tracked (Figure 10c and d and Table 1) for the same duration. In this case, the mean eddy diameter is larger than for ROMS-SWIM $(109 \pm 20 \mathrm{~km})$. Their mean amplitude $(11 \pm 4$ $\mathrm{cm})$ and life time (25 \pm 21 days) are consistent with ROMS-SWIM, considering the respective standard deviations. On average for the 8 years, the data indicate that cyclonic eddies are present in the region $54 \%$ (58\%) of the time for ROMS-SWIM (AVISO). If we reduce the study to the eddies generated in the box $\left[33.5^{\circ}-34.5^{\circ} \mathrm{E}\right.$; $25.5^{\circ}-26.5^{\circ} \mathrm{S}$ ] used to define the presence of a lee eddy in the composite analysis, the number of tracked cyclonic eddies (red trajectories on Figure 10a and c) is reduced to 33 (36) with a mean life duration of $18 \pm 15$ days (21 \pm 24 days) for ROMS-SWIM (AVISO). In that case, on average for the 8 years, cyclonic eddies are present in this smaller region $20.5 \%(25.5 \%)$ for ROMS-SWIM AVISO) of the time as deduced before from the DBLE occurrence time series $(22.4 \%$ and $23.0 \%)$. Note that the standard deviations of the statistical life durations are comparable to their respective mean values, for both model and AVISO datasets, whatever the selected region. This is discussed in section 4.

Around half of the eddies stay in the Bight and can be considered as a DBLE as strictly defined using the composite criteria. However, a fraction are generated further eastward or northward of the smaller region defined above and eventually move southward toward the northern Agulhas Current. In ROMS-SWIM (AVISO), $20.6 \%$ $(29.4 \%)$ cyclonic eddies reach $27^{\circ} \mathrm{S}$ and $5.9 \%(1.5 \%)$ reach $28^{\circ} \mathrm{S}$.

\subsection{Inhambane Cyclones}

As discussed above, DBLE onset depends on interactions with the surrounding dynamical features. Among them we suggest in this section that cyclones formed north of the Delagoa Bight may be important. 

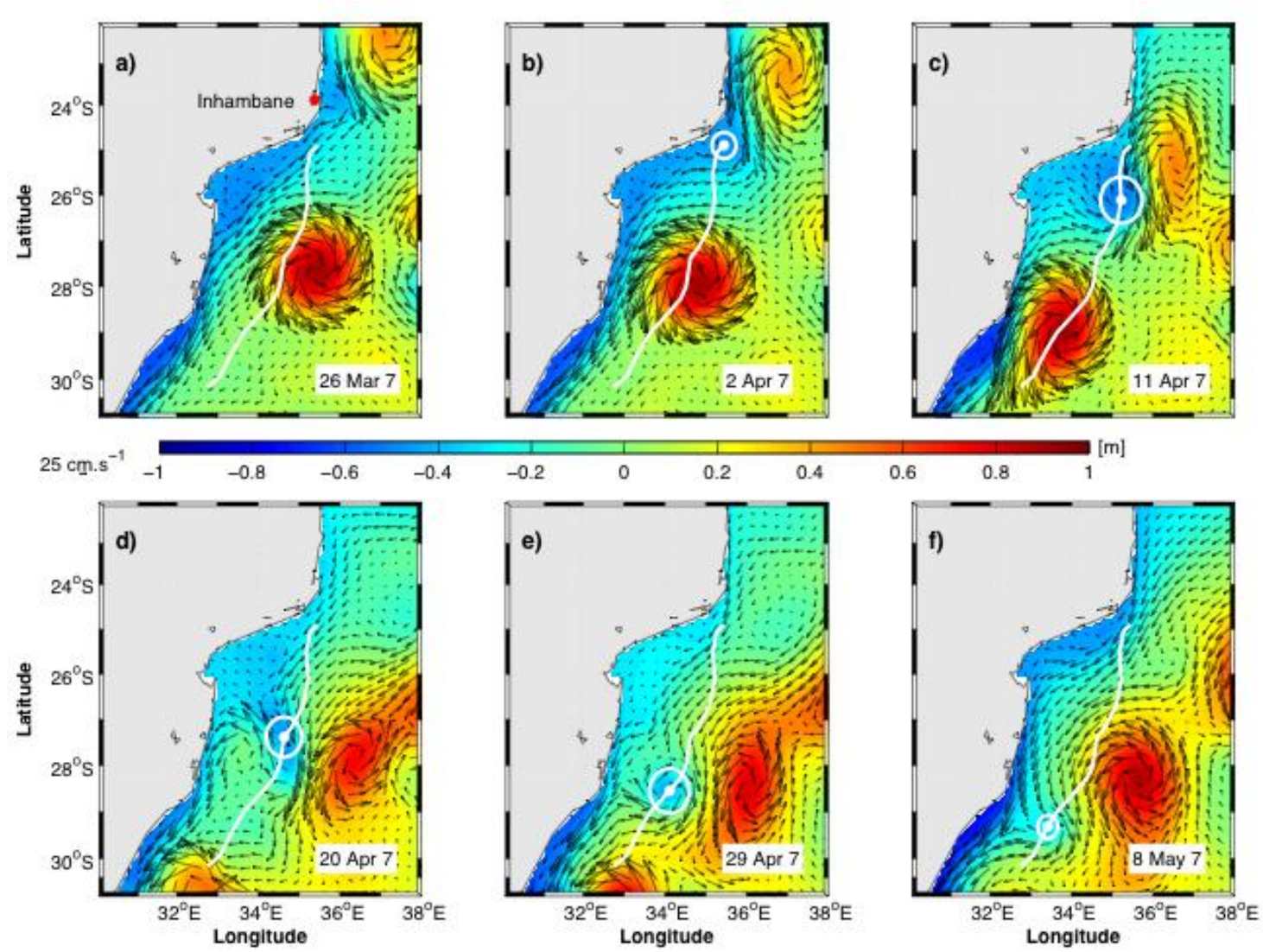

Figure 11: Snapshots of model SSH and surface ocean currents during the generation of a typical Inhambane Cyclone whose position, size and trajectory (from the tracking method) are shown by the white circle and line.

Figure 11 presents a succession of horizontal maps of SSH and surface currents illustrating the formation of such a cyclone offshore of Inhambane $\left(35.39^{\circ} \mathrm{E}, 23.87^{\circ} \mathrm{S}\right)$ and its subsequent fate until its dissipation past the Natal Bight. The formation process results from the shedding of nearshore waters as the nearshore flow is intensified owing to the presence of an anticyclonic Mozambique Channel ring (Figure 11a). This meander propagates southward, constrained by the flow and the presence of the offshore ring. It subsequently detaches as a cyclonic eddy (which we have called an "Inhambane Cyclone", hereafter IC) just offshore off the Delagoa Bight (Figures 11b and 11c). At this stage, the IC exerts an influence on the circulation in the northeastern part of the Bight (Figure 11c). It still propagates southward and reaches the southern part of the Bight in 2 to 3 weeks (Figure 11d). It ultimately vanishes in the northern Agulhas current (Figure 11f). 


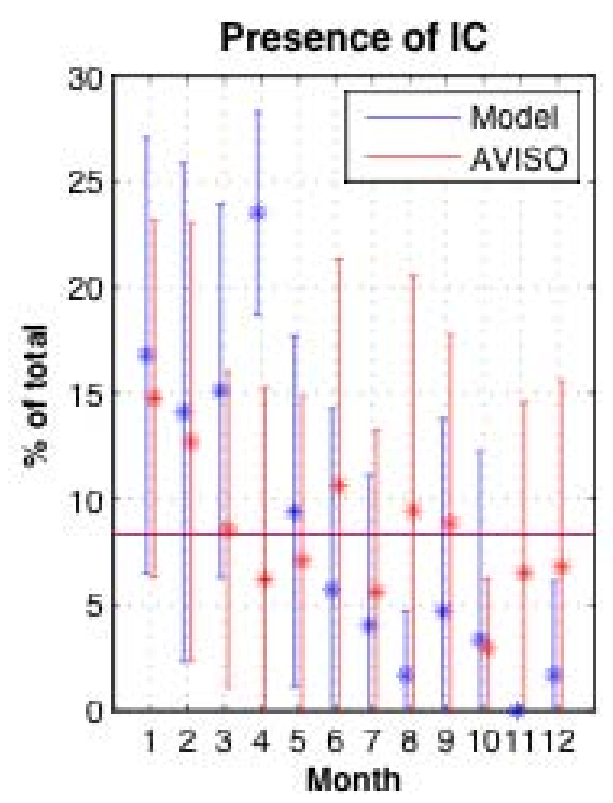

Figure 12: Monthly climatology of ICs in model outputs (blue) and AVISO (red): monthly mean occurrences normalised by the total number of occurrences (asterisks) and standard deviation calculated over the 8-year study period for each data set (vertical lines). The horizontal line provides the percent of occurrences assuming all months have the same number of events.

Careful inspection of SSH and surface current sequences reveals a preferential occurrence of ICs during the first four months of the year in ROMS-SWIM (Figure 12). Although ICs can be also observed with similar properties in AVISO altimetry, the seasonality is less marked perhaps as a consequence of our climatological oceanic boundary conditions.

\begin{tabular}{|l|l|l|l|l|}
\hline IC & $\begin{array}{l}\text { Number of } \\
\text { Eddies }\end{array}$ & $\begin{array}{l}\text { Diameter }[\mathrm{km}] \\
\text { Mean (std) } / \text { min-max }\end{array}$ & $\begin{array}{l}\text { Mean (std) } \\
\text { Life Time [days] }\end{array}$ & $\begin{array}{l}\text { Mean (std) } \\
\text { Amplitude [cm] }\end{array}$ \\
\hline AVISO & 32 & $93(13) / 67-118$ & $16(12)$ & $8(3)$ \\
\hline Model & 24 & $75(23) / 30-118$ & $47(56)$ & $11(8)$ \\
\hline $\begin{array}{l}\text { Model } \\
\text { D }>60 \mathrm{~km}\end{array}$ & 13 & $86(15) / 69-115$ & $39(48)$ & $13(8)$ \\
\hline
\end{tabular}

Table 2: Summary of Inhambane cyclonic eddy characteristics estimated from the tracking system

The eddy detection algorithm presented previously is used to track ICs from ROMS-SWIM and AVISO as cyclonic structures generated in the box off Inhambane seen in Figure 13. 24 ICs are detected over 8 years of simulation in ROMS-SWIM, with a mean radius of about 35-40 km (Figure 13a and b and Table 2). Most of the 
ICs propagate southward along the coast but several tracks also show an offshore displacement induced by large Mozambique rings. Most importantly, note also that several tracks unambiguously demonstrate the influence of ICs on Delagoa Bight dynamics. These patterns of offshore and onshore IC displacement are not seen in AVISO (Figure 13c). 32 eddies were detected in this case, but fewer travelled southward and none eastward. The mean radius in the AVISO case is about $50 \mathrm{~km}$, probably due to the coarser resolution of the product (Figure 13d, Table 2). The mean life time of eddies detected in AVISO are $16 \pm 12$ days, much lower than the $47 \pm 56$ days seen with ROMS-SWIM.
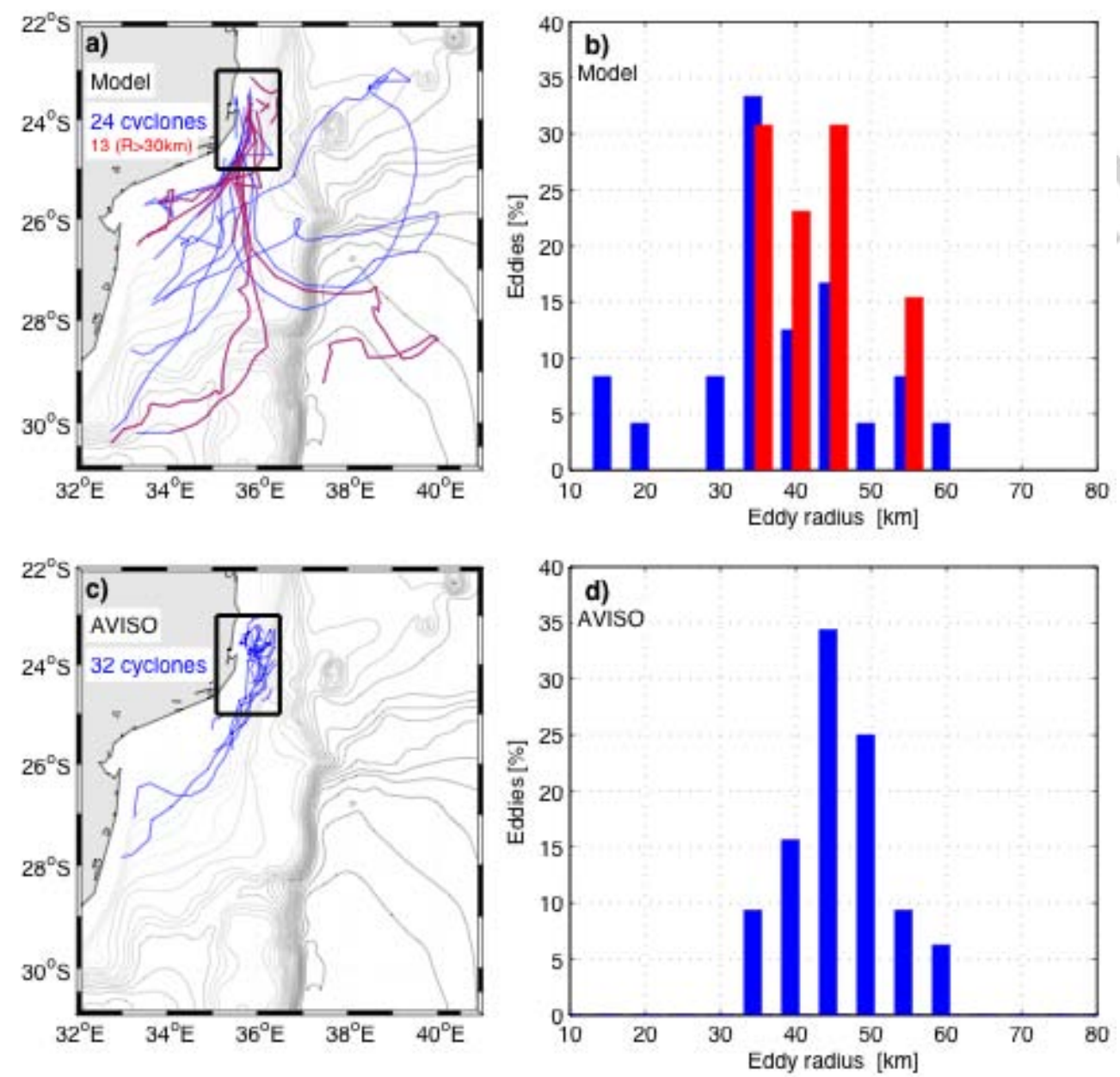

Figure 13: Trajectories (left) and radius distribution (right) of detected ICs in the model simulation (top) and in AVISO altimetry data (bottom). Trajectories (left) and radius distribution (right) of detected ICs with radius greater than $30 \mathrm{~km}$ in the model simulation are shown in red on a) and b).

In addition, Figure 13a and $\mathrm{b}$ shows in red the results of tracking only eddies with a radius greater than $30 \mathrm{~km}$ in the model outputs. The eddy radius distribution is in this case more comparable between Model and AVISO data 
(Figure13 b and d and Table 2). Most of the offshore IC displacement observed in the modelled trajectories are associated with small cyclonic eddies. Nevertheless, the trajectories still show some differences between AVISO and model tracking.

The small size of ICs and their speed of propagation make them difficult to track with AVISO. This could explain the difference between AVISO and the model with regard to IC characteristics. A few ICs seem to strongly interact with their initiating anticyclones reproducing features very similar to the dipole described by Roberts et al. [2014] (not shown).

\section{Discussion}

In this study, we have documented the dynamics of the cyclonic lee eddy that occurs in the Delagoa Bight region. Another recurrent cyclonic eddy (IC) found further north is also investigated, which may affect the DBLE life cycle. Since direct observations are sparse, we have developed a realistic modelling approach to reproduce the regional circulation. Diagnostics on model outputs are also performed, and when possible, on AVISO satellite observations. The adequacy of these observations in describing the dynamics in the Delagoa Bight region might be questionable. First of all, SSH observations include a mean dynamic topography MDT [Rio et al. 2014] in which errors are substantial along the coast $(2-4 \mathrm{~cm}$ within Delagoa Bight). Actually, the imprint of DBLE is already visible on $\mathrm{MDT}$, centred at $\left(26.5^{\circ} \mathrm{S}, 33.25^{\circ} \mathrm{E}\right)$, to the southwest compared to the DBLE centre in the model, and this imprint falls within the estimated error in MDT. In addition, DBLE and IC average diameters covers less than 4 points of AVISO mapped product. Therefore, the uncertainty of AVISO datasets must be kept in mind when describing the dynamics in the Delagoa Bight region. For example, we have noted that the DBLE is estimated larger (while IC is estimated smaller) in AVISO than in the model dataset. Taking into account the estimated error in AVISO product, as well as the standard deviation associated with each mean estimate, these differences are clearly not significant.

ROMS-SWIM simulation outputs should not be taken for granted either, as there are a few possible caveats in this numerical study. River runoffs and tides are ignored in the model, which may explain some of the minor biases of the simulation in the upper ocean compared to in situ measurements. Atmospheric forcings are climatological and have a relatively low resolution, which may also be responsible for the biases in water masses 
properties. Oceanic boundary conditions are also taken from a climatologically forced model which may explain the exaggerated seasonality in passing Mozambique Channel rings [Halo et al., 2014a] and, hence the seasonality of model ICs generation not found in AVISO. In addition, the coastal countercurrent produced by the model in DBLE conditions is intermittent. Observations are scarce but suggest systematic presence of that countercurrent [Lamont et al., 2010]. The fact that a few processes are not included in the model, like the rectified effects from synoptic atmospheric forcing, may explain this discrepancy. Those model biases being acknowledged, it is important to remind the reader that the well-known influence of remotely generated mesoscale activity on Delagoa Bight is expected to be represented in our configuration. Indeed, lateral boundary conditions are provided at high frequency (3-day averages) from a larger ROMS configuration that has been shown to reproduce the mesoscale dynamics in the Mozambique Channel [Halo et al., 2014].

With regard to the tracking of eddies that is applied to both observed and modelled $\mathrm{SSH}$, this method is admittedly not appropriate to capture events of merging and splitting of eddies. Hence the diagnosed life duration of the detected mesoscale structures may not be fully representative of the entire life cycle of eddies, particularly in a very dynamically active region like the Mozambique Channel. This uncertainty may contribute to increasing the standard deviation of DBLE and IC life durations, both in observations and model outputs.

What controls the onset of the DBLE remains unclear. We have suggested two favourable conditions, relying on the location of mesoscale processes and the intensity of the southward flow along the African coast. If the DBLE can be seen as a standing perturbation of a southward mean flow past a topographic feature, we could make an analogy with standing planetary waves in the atmosphere [Rossby et al., 1939] using here coastal trapped waves as done in St Helena Bay for the Benguela [Penven, 2000]. The wave length excited is selected here by the phase speed countering the mean flow. Using barotropic shelf waves for simplicity, the dispersion relation is given by Wilkin and Chapman [1987]. Using a bottom topography of the form $H=H_{\max } e^{-2 \lambda\left(Y_{\max }-y\right)}$ (where y is the offshore distance, $\mathrm{Y}_{\max }$ is the distance to the shelf break and the topographic parameters chosen as $\lambda=7 \mathrm{x}$ $10^{-6}$ and $H_{\max }=500 \mathrm{~m}$ [Penven, 2000; Wilkin and Chapman, 1987]), if we limit the maximum wave length to the alongshore length of the bay (approx. $200 \mathrm{~km}$ ), this would select a maximum southward current of $0.7 \mathrm{~m} \mathrm{~s}^{-1}$. This is consistent with the DBLE characteristics. If the southward current is faster, then the bay cannot host a stationary shelf wave, and hence no DBLE occurs. 
As mentioned above, an important aspect of DBLE onset and more generally Delagoa Bight dynamics is the modulation of the southward coastal transport along the Mozambican coast. Although previous studies have emphasised the fact that no coherent "Mozambique Current" exists in the Channel and that the circulation is dominated by anticyclonic eddies drifting poleward [Schouten et al., 2003; Ridderinkhof and de Ruijter, 2003; Harlander et al., 2009; Lutjeharms et al., 2012], our numerical simulation suggests that a southward current along the Mozambican coast is permanent as far north as Ponta Závora albeit with important fluctuations of the transport at the latitude of the Bight. This finding is consistent with another model solution [Figure 2 in Lutjeharms et al., 2012] and would need to be confirmed observationally (see appendix for further discussion on this topic). Overall, the Delagoa Bight region appears to be a key transition zone where mesoscale activity exerts a fundamental control on the boundary current and coastal features like the DBLE.

Other transient cyclonic eddies travelling through the Bight are generated north of Ponta Závora near Inhambane coast, perhaps as a consequence of nearshore boundary layer separation triggered by anticyclonic Mozambique Channel rings. These Inhambane Cyclones (IC) generally migrate southward following various pathways potentially interacting with the southward coastal current, the dynamics of the Delagoa Bight and the large anticyclones in the Mozambique Channel. As IC generation is generally associated with the presence of a strong anticyclonic eddy passing close to the cape and then inducing strong southward current along the coast, it is most likely that IC generation has a negative effect on a DBLE onset.

\section{Conclusion}

In this study, we document the dynamics of the Delagoa Bight region, a region to the south of the Mozambique Channel that is important for its high levels of productivity and hence its rich marine ecosystem. Sparse available observations, mostly from satellite observations of $\mathrm{SSH}$, are complemented by an eddy resolving regional simulation that satisfactorily reproduces the mean circulation, mesoscale activity (particularly the influence of remotely generated mesoscale features) and water mass properties in this region.

The dynamics in the Delagoa Bight region are dominated by a cyclonic non-permanent feature which is observed in a stationary form, centred around $26^{\circ} \mathrm{S}-34^{\circ} \mathrm{E}$, the so-called Delagoa Bight Lee Eddy, which is 
consistent with previous observations [Lutjeharms and da Silva, 1988; Lamont et al., 2010]. In our model and AVISO observations, the DBLE is present at least $25 \%$ of the time. Its frequency of occurrence does not exhibit any seasonal variability. The diameter of the core varies between 60 and $150 \mathrm{~km}$ (lower than the previous estimate of $180 \mathrm{~km}$ from Lutjeharms and da Silva [1988]) and the average life time exceeds 20 days. In the case of presence of the lee eddy in the Bight, a doming in temperature and salinity occurs and is particularly marked below $250 \mathrm{~m}$ but the most remarkable difference between situations with and without DBLE, is the presence of a northward, surface intensified, coastal countercurrent in the former.

The nearshore flow disturbance induced by the coastline and bathymetry irregularity promotes cyclonic conditions in the bight as a consequence of vortex stretching (and perhaps frictional processes that we do not expect to represent properly at the horizontal resolution used here [Molemaker et al. 2014]). Under favourable conditions that we have strived to identify but will need further investigation, cyclonic vorticity is able to organise and maintain itself in the form of a DBLE. The most favourable of those combine the presence of a large anticyclonic eddy just south of the Bight and a weak or moderate southward coastal current near Ponta Závora.

Other transient cyclonic eddies are generated north of Ponta Závora near Inhambane in cases where anticyclonic Mozambique Channel rings approach the shore. Our analyses suggest a possible interaction between DBLE and the generally southwestward moving ICs. However, considering the small spatial scale of IC compared to the horizontal resolution of AVISO mapped products, model outputs regarding IC characteristics and potential impact on DBLE need to be ascertained by in situ observations.

Finally, we emphasise the need for continuous observations of the main currents in this region (the countercurrent to the west of the Bight, the circulation around the Cape, and the larger scale alongshore southward flow) to clarify their temporal variability and role in the dynamics of the Delagoa Bight. Our efforts aimed at better understanding the dynamics of the DBLE should pave the way for an investigation of its effect on the biogeochemistry. Cyclonic eddies are known to impact the biogeochemistry and ecosystems functioning in major ways [Chenillat et al, 2015 and references therein]. Existing observations suggest this is true for the DBLE although the processes at work would need to be clarified. 


\section{Appendix}

Our model simulations cover a substantial fraction of the southern Mozambique Channel where recent studies have suggested the predominance of eddies rather than a continuous southward flow, historically described as the "Mozambique Current". Indeed, Lutjeharms et al. [2012] have shown that "a continuous western boundary current along the Mozambican shelf edge may on occasion come about, but that this is a very exceptional event that invariably lasts for only a short time". This result applied to the whole Mozambique Channel, but Figure 2 of Lutjeharms et al. [2012] also indicates that south of $24^{\circ} \mathrm{S}$, a continuous current seems to be present in any case. A careful analysis of ROMS-SWIM current at $100 \mathrm{~m}$ depth shows the existence of an along coast southward current for more than $94 \%$ of the time based on the 8 years of 3-day averaged model outputs. Figure 14a shows an illustration of this almost continuous current along the coast (following the $1000 \mathrm{~m}$ isobath) for May, 14 of year 4. The temporal distribution of the along isobath component of the current at $100 \mathrm{~m}$ depth for six locations along the coast are shown on Figure 14b. From north to south, the along isobath velocities are positive (corresponding to a northward or northeastward flow) for only $2.0,2.9,5.8,2.9,0.8$ and $2.6 \%$ of the total length of the time series. On average, the mean along isobath velocity varies from $42 \pm 26 \mathrm{~cm} \mathrm{~s}^{-1}$ south of Delagoa Bay (green triangle on Figure 14a) to $76.7 \pm 32.9 \mathrm{~cm} \mathrm{~s}^{-1}$ at $30^{\circ} \mathrm{S}$ (pink triangle on Figure 14a). There is no long-term measurement of velocity available in the area. Nevertheless, an ADCP survey undertaken along the shelf edge between 9-Mile Reef and Leven Canyon (from $-27.4^{\circ} \mathrm{S}$ to $28^{\circ} \mathrm{S}$ around the black triangle on Figure 14a) on April 2002 [Roberts et al., 2006] revealed a strong southward flow throughout the survey area that commonly reached $50-75 \mathrm{~cm} \mathrm{~s}^{-1}$, which is comparable to the mean value provided by the model at the same place $(62.5 \pm 28.3 \mathrm{~cm}$ $\left.s^{-1}\right)$.
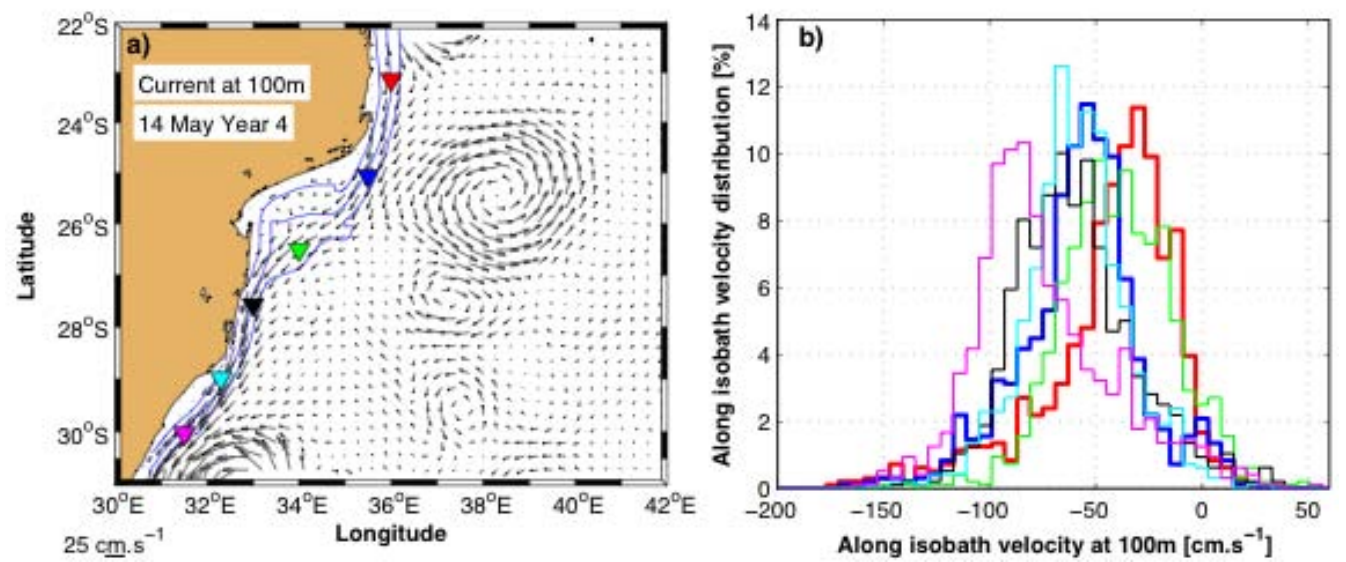

Figure 14: (a) Current a $100 \mathrm{~m}$ depth for May, 14 of year 4. 200, 500 and 1000 isobaths are represented in blue line. (b) Probability density function of along isobath velocity at $100 \mathrm{~m}$ depth for the different locations shown on 
(a). Negative values indicate a southward or southwestward flow.

\section{References}

Arbic B.K, Scott, R.B. , Chelton, D.B., Richman, J.G. and J.F. Shriver (2012). Effects on stencil width on surface ocean geostrophic velocity and vorticity estimation from gridded satellite altimeter data, J. Geophys. Res., vol117, C03029, doi:10.1029/2011JC007367.

Barlow, R., Kyewalyanga, M., Sessions, H., van den Berg, M. and T. Morris (2008). Phytoplankton pigments, functional types, and absorption properties in the Delagoa and Natal Bights of the Agulhas ecosystem, Estuarine, Coastal and Shelf Science, 80:201-211.

Beckmann, A. and D.B. Haidvogel (1993). Numerical simulation of flow around a tall isolated seamount. part I: Problem formulation and model accuracy, Journal of Physical Oceanography, 23:1736-1753.

Biastoch, A. and W. Krauss (1999). The Role of Mesoscale Eddies in the Source of the Agulhas Current, Journal of Physical Oceanography, 29:2003-2317.

Carpine-Lancre, J., Fisher, R., Harper, B., Hunter, P., Jones, M., Kerr, A., Laughton, A., Ritchie, S., Scott, D. and M. Whitmarsh (2003). The History of GEBCO 1903-2003: The 100-Year Story of the General Bathymetric Chart of the Oceans, Lemmer, Netherlands., GITC, 140pp.

Casey, K.S. and P. Cornillon (1999). A comparison of satellite and in situ based sea surface temperature climatologies, Journal of Climate, 12:1848-1863.

Collins, C., Hermes, J.C. and Reason, C.J.C. (2014). Mesoscale activity in the Comoros Basin from satellite altimetry and a high resolution ocean, Journal of Geophysical Research, 118:3114-3127. doi:10.1002/2014JC010008

Cushman-Roisin, B. (1994). Introduction to Geophysical Fluid Dynamics. Prentice Hall.

da Silva, A.M., Young, C.C. and S. Levitus (1994). Atlas of surface marine data 1994, vol. 1 algorithms and procedures, NOAA Atlas NESDIS 6. U.S. Department of Commerce, NOAA, NESDIS.

D'Asaro, E.A. (1988). Generation of submesoscale vortices: A new mechanism, Journal of Geophysical Research, 93(C6), 6685-6693.

de Ruijter, W.P.M., Ridderinkhof, H., Lutjeharms, J.R.E., Schouten, M.J. and C. Veth (2002). Observations of the flow in the Mozambique Channel, Geophysical Research Letters, 29(10), 3-5.

DiMarco, S.F., Chapman, P., Nowlin Jr., W.D., Hecker, P., Donohue, K., Luther, M., Jonson, G.C. and J. Toole 
(2002). Volume transport and property distribution of the Mozambique Channel, Deep Sea Research II, 49:1482-1511.

Donguy, J.R. and B. Piton (1991). Mozambique Channel Revisited, Oceanologica Acta, 14(6):549- 558.

Chenillat, F., Franks, P.J.S., Rivière, P., Capet, X., Grima, N. and B. Blanke (2015). Plankton dynamics in a cyclonic eddy in the Southern California Current System. J. Geophys. Res. Oceans. Accepted Author Manuscript. doi:10.1002/2015JC010826

Centurioni, L.R., OhImann, J.C. and P.P. Niiler (2008). Permanent Meanders in the California Current System. Journal of Physical Oceanography, 38(8), 1690-1710. doi:10.1175/2008JPO3746.1

Haidvogel, D.B. and A. Beckmann (1999). Numerical Ocean Circulation Modeling, vol. 2, Series on Environmental Science and Management, Imperial Coll. Press, London.

Halo, I., Backeberg, B., Penven, P., Ansorge, I., Reason, C. and J. Ulgren (2014a). Eddy properties in the Mozambique Channel: A comparison between observations and two Numerical Ocean Circulation Models, Deep Sea Research II, 100:38-53.

Halo, I., Penven, P., Backeberg, B., Ansorge, I., Shillington, F. and R. Roman (2014b). Mesoscale eddy variability in the southern extension of the East Madagascar Current: Seasonal cycle, energy conversion terms, and eddy mean properties, Journal of Geophysical Research, 119, 7324-7356.

Hancke, L., Roberts, M.J. and J.F. Ternon (2014). Surface drifter trajectories highlight flow pathways in the Mozambique Channel. Deep-Sea Research Part II: Topical Studies in Oceanography, 100, 27-37. doi:10.1016/j.dsr2.2013.10.014

Harlander, U., Ridderinkhof, H., Schouten, M.W. and W.P.M. de Ruijter (2009). Long-term observations of transport, eddies, and Rossby waves in the Mozambique Channel, Journal of Geophysical Research, 114(C2), 1-15.

Kyewalyanga, M.S., Naik, R., Hedge, S., Raman, M., Barlow, R. and M.J. Roberts (2007). Phytoplankton biomass and primary production in Delagoa Bight Mozambique: Application of remote sensing, Estuarine Coastal and Shelf Science, 74:429-436.

Lamont, T., Roberts, M., Barlow, R. and M. van den Berg (2010). Circulation patterns in the Delagoa Bight, Mozambique, and the influence of deep ocean eddies, African Journal of Marine Science, 32(3):553-562.

Large, W., McWilliams, J. and S. Doney (1994). Oceanic Vertical Mixing: A review and model with nonlocal layer parameterization, Review of Geophysics, 32(4):363-403.

Lutjeharms, J.R.E. (2006a). The Agulhas Current. Vol. 1, 329pp., Springer, Berlin. 
Lutjeharms, J.R.E. (2006b). The Ocean environment off southeastern Africa: a review, South African Journal of Science, 102:419-426.

Lutjeharms, J.R.E. and J. da Silva (1988). The Delagoa Bight eddy, Deep Sea research, 35:619-634.

Lutjeharms, J.R.E., Biastoch, A., van der Werf, P.M., Ridderinkhof, H. and W.P.M. de Ruijter (2012). On the discontinuous nature of the Mozambique Current, South African Journal of Science, 108(1/2), 5 pp.

Manyilizu, M., Dufois, F., Penven, P. and C. Reason (2014). Interannual variability of sea surface temperature and circulation in the tropical western Indian Ocean, African Journal of Marine Science, 36:233-252. doi:10.2989/1814232X.2014.928651

Marchesiello, P., McWilliams, J.C. and A. Shchepetkin (2001). Open boundary condition for long-term integration of regional oceanic models, Ocean Modelling, 3(1-2):1-20.

Marchesiello, P., Debreu, L. and X. Couvelard (2009). Spurious diapycnal mixing in terrain-following coodinate models: The problem and solution, Ocean Modelling, 26(3-4):156-169.

Martin, A. (1981). The Influence of the Agulhas Current on the physiographic development of the northernmost Natal valley (S.W. Indian Ocean), Marine Geology, 39:259-276.

McGillicuddy, D. and A. Robinson (1997). Eddy-induced nutrient supply and new production in the Sargasso Sea, Deep Sea Research I, 44:1427-1450.

Molemaker, M.J., McWilliams, J.C. and W.K. Dewar (2015). Submesoscale Instability and Generation of Mesoscale Anticyclones near a Separation of the California Undercurrent. J. Phys. Oceanogr., 45, 613-629.

Okubo, W. (1970). Horizontal dispersion of floatable particles in the vicinity of velocity singularities such as convergencies, Deep Sea Research and Oceanographic Abstract, 17(3):445-454.

Paula, J., Pinto, I., Guambe, I., Monteiro, S. and D. Gove (1998). Seasonal cycle of planktonic communities at Inhaca Island, southern Mozambique, Journal of Plankton Research, 20(11):2165-2178.

Penven, P. (2000). A numerical study of the Southern Benguela circulation with an application to fish recruitment, Ph.D. thesis, Université de Bretagne Occidentale, Brest, France, 160 pp.

Penven, P., Echevin, V., Pasapera, J., Colas, F. and J. Tam (2005). Average circulation, seasonal cycle, and mesoscale dynamics of the Peru Current System: a modeling approach, Journal of Geophysical Research, 110, C10021.

Penven, P., Marchesiello, P., Debreu, L. and J. Lefevre (2008). Software tools for pre- and post-processing of oceanic regional simulations, Environmental Modelling \& Software, 23(5):660-662.

Ridderinkhof, H. and W.P.M. de Ruijter (2003). Moored current observations in the Mozambique Channel, Deep- 
Sea Research II: Topical Studies in Oceanography, 50(12-13):1933-1955.

Rio, M.-H., S. Mulet, and N. Picot (2014), Beyond GOCE for the ocean circulation estimate: Synergetic use of altimetry, gravimetry, and in situ data provides new insight into geostrophic and Ekman currents, Geophys. Res. Lett., 41, doi:10.1002/2014GL061773.

Roberts, M.J., Ribbink, A.J., Morris, T., van den Berg, M.A., Engelbrecht, D.C. and R.T. Harding (2006). Oceanographic environment of the Sodwana Bay coelacanths (Latimeria chalumnae), South Africa. South African Journal of Science, 102(October), 435-443.

Roberts, M.J., Ternon J.-F. and T. Morris (2014). Interaction of dipole eddies with the western continental slope of the Mozambique Channel, Deep Sea Research Part II: Topical Studies in Oceanography, 100:54-67.

Rossby C.-G. and Collaborators (1939). Relation between variations in the intensity of the zonal circulation of the atmosphere and the displacements of the semi-permanent centers of action, Journal of Marine Research, 2 , $38-55$,

Saetre, R. and J. da Silva (1984). The circulation of the Mozambique Channel, Deep Sea Research Part A. Oceanographic Research Papers, 31(5):485-508.

Schouten, M., de Ruijter, W.P.M., Vanleeuwen, P. and H. Ridderinkhof (2003). Eddies and variability in the Mozambique Channel, Deep Sea Research Part II: Topical Studies in Oceanography, 50(12-13), 1987-2003.

Shi, C. and D. Nof (1994). The distruction of lenses and generation of wodons, Journal of Physical Oceanography, 24:1120-1136.

Shchepetkin, A. and J.C. McWilliams (2005). The regional oceanic modeling system (ROMS): a split-explicit, free-surface, topography-following-coordinate oceanic model, Ocean Modelling, 9(4):347-404.

Weiss, J. (1991). The dynamics of enstrophy transfer in two-dimensional hydrodynamics, Physica D: Nonlinear Phenomena, 48(2-3):273-294.

Wilkin, J.L., and D.C. Chapman (1987). Scattering of continental shelf waves at a discontinuity of the shelf width, J. Phys. Oceanogr., 17, 713-724.

\section{Research Highlights}

- Mean circulation and mesoscale activity near Delagoa Bight are realistically simulated.

- The model produces a semi-permanent cyclonic lee eddy in Delagoa Bight.

- Favourable conditions to the onset of the lee eddy are described. 
- Transient cyclonic eddies travelling through the Bight are generated north of P. Z. vora. 